\title{
Title: Demographic tradeoffs predict tropical forest dynamics
}

Authors: Nadja Rüger ${ }^{1,2, *}$, Richard Condit ${ }^{3,4}$, Daisy H. Dent ${ }^{2,5}$, Saara J. DeWalt ${ }^{6}$, Stephen P. Hubbell $^{2,7}$, Jeremy W. Lichstein ${ }^{8}$, Omar R. Lopez ${ }^{2,9}$, Christian Wirth ${ }^{1,10,11}$, Caroline E. Farrior ${ }^{12}$.

\section{Affiliations:}

${ }^{1}$ German Centre for Integrative Biodiversity Research (iDiv) Halle-Jena-Leipzig, Deutscher Platz 5e, 04103 Leipzig, Germany.

${ }^{2}$ Smithsonian Tropical Research Institute, Apartado 0843-03092, Balboa, Ancón, Panama.

${ }^{3}$ Field Museum of Natural History, 1400 S. Lake Shore Dr., Chicago, 60605, IL, USA.

${ }^{4}$ Morton Arboretum, 4100 Illinois Rte. 53, Lisle, 60532, IL, USA.

${ }^{5}$ Biological and Environmental Sciences, University of Stirling, Stirling, FK9 4LA, UK.

${ }^{6}$ Department of Biological Sciences, Clemson University, Clemson, SC 29634, USA.

${ }^{7}$ Department of Ecology and Evolutionary Biology, University of California, Los Angeles, CA 90095, USA.

${ }^{8}$ Department of Biology, University of Florida, Gainesville, FL 32611, USA.

${ }^{9}$ Instituto de Investigaciones Científicas y Servicios de Alta Tecnología (INDICASAT), Edificio 209, Clayton, Panama.

${ }^{10}$ Systematic Botany and Functional Biodiversity, Institute of Biology, University of Leipzig, Johannisallee 21-23, 04103 Leipzig, Germany.

${ }^{11}$ Max-Planck-Institute for Biogeochemistry, Hans-Knöll Str. 10, 07745 Jena, Germany.

12 Department of Integrative Biology, University of Texas at Austin, Austin, TX 78712, USA.

*Correspondence to: nadja.rueger@idiv.de

Abstract: Understanding tropical forest dynamics and planning for their sustainable management requires efficient, yet accurate, predictions of the joint dynamics of hundreds of tree species. With increasing information on tropical tree life-histories, our predictive understanding is no longer limited by species data, but by the ability of existing models to make use of it. Using a demographic forest model, we show that the basal area and compositional changes during forest succession in a Neotropical forest can be accurately predicted by representing tropical tree diversity (hundreds of species) with only five functional groups spanning two essential tradeoffs - the growth-survival and stature-recruitment tradeoffs. This data-driven modeling framework substantially improves our ability to predict consequences of anthropogenic impacts on tropical forests.

One Sentence Summary: Representing tropical tree diversity with two demographic tradeoffs yields accurate predictions of tropical forest dynamics.

Main Text: Tropical forests are highly dynamic. Only about $50 \%$ of the world's tropical forests are undisturbed old-growth forests (1). The remaining half comprises forests regenerating after previous land use, timber or fuelwood extraction, or natural disturbances. Even unmanaged oldgrowth forests are a dynamic mosaic of patches recovering from single- or multiple treefall gaps 
(2). Thus, understanding how forest structure and composition of the diverse tree flora change during recovery from disturbance is fundamental to predict carbon dynamics, as well as to plan sustainable forest management (3). Despite the importance of regenerating tropical forests for the global carbon cycle and timber industry, our mechanistic understanding and ability to forecast compositional changes of these forests remains severely limited (4).

Conceptually, tropical forest succession has been viewed mostly through a onedimensional lens distinguishing species along a fast-slow life-history continuum, or growthsurvival tradeoff (4-6). 'Fast' species are light-demanding, grow quickly, but survive poorly, and dominate early successional stages, while 'slow' species are shade-tolerant, grow slowly, but survive well, and reach dominance in later successional stages. However, several studies suggest that tropical tree communities are also structured along a second major tradeoff axis that is orthogonal to the growth-survival tradeoff: the stature-recruitment tradeoff $(7,8)$. The staturerecruitment tradeoff distinguishes long-lived pioneers (LLPs) from short-lived breeders (SLBs). LLPs grow fast and live long and hence attain a large stature, but exhibit low recruitment. SLBs grow and survive poorly and hence remain short-statured, but produce large numbers of offspring (8). However, we are lacking a systematic assessment of how important these tradeoffs are for tropical forest dynamics.

To evaluate the importance of the growth-survival and stature-recruitment tradeoffs for tropical forest dynamics, we parameterized the Perfect Plasticity Approximation (PPA) model (9, 10) with demographic tradeoffs derived from forest inventory data. The model simulates the dynamics of a potentially large number of species based on a small set of demographic rates (growth, survival, recruitment) and accounts for height-structured competition for light by distinguishing up to four canopy layers (11). Canopy gaps are filled by the tallest trees from lower canopy layers, without regard for their horizontal position (perfect plasticity assumption, 9).

Our study site is the tropical moist forest at Barro Colorado Island (BCI), Panama, where recruitment, growth and survival of individual trees have been monitored in a 50-ha plot for over 30 years $(2,11,12)$. To account for the dependence of these demographic rates on light availability, we assigned all monitored individuals of 282 tree and shrub species to one of four canopy layers based on their size and the size of their neighbors $(11,13)$ and estimated model parameters (annual diameter growth and survival rates) for each species in each canopy layer (8). Additionally, we calculated species recruitment rates per unit of basal area. A dimension reduction of model parameters (weighted PCA, 14) reveals the two demographic tradeoffs, i.e. the growth-survival tradeoff and the stature-recruitment tradeoff, which together explain $65 \%$ of demographic variation among the 282 species (Fig. 1).

\section{$<$ INSERT FIG. 1>}

Fig. 1: Demographic tradeoffs for 282 tree species at BCI, Panama. Arrows show loadings of a weighted PCA on annual diameter growth and survival rates of individuals $\geq 1 \mathrm{~cm}$ diameter in four canopy layers (where 1 is full sun and 4 is shaded by 3 canopy layers) and the number of sapling recruits per unit of basal area. Colored dots are locations in demographic space of plant functional types that were used in model scenarios 1 and 3. 
Our goal here is to explore whether this low-dimensional demographic tradeoff space can capture tropical forest dynamics, and if so, how much demographic diversity is necessary to accurately predict changes in basal area (a proxy for carbon storage in aboveground biomass) over time. We used species' positions in the tradeoff space to estimate model parameters for all 282 species (11), thus smoothing across observed relationships between demographic rates. We simulated forest dynamics under four scenarios that differed in the number of tradeoffs (1 versus 2) and level of demographic diversity (number of simulated species or plant functional types PFTs; Table 1, Fig. 2A). We tested model performance for the 50-ha old-growth plot at BCI (also used to derive demographic rates) and for a chronosequence of nearby secondary forests that share a similar topography, soil, and the majority of tree species (15).

Table 1: Model scenarios. Model scenarios differ in the number of included tradeoffs and the level of demographic diversity. LLP - long-lived pioneers, SLB - short-lived breeders.

\begin{tabular}{lll}
\hline Scenario & Tradeoffs & Demographic diversity \\
\hline 1 & Growth-Survival & 3 PFTs (fast, intermediate, slow) \\
2 & Growth-Survival & 282 species \\
3 & Growth-Survival, Stature-Recruitment & 5 PFTs (fast, slow, LLP, SLB, \\
& & intermediate) \\
4 & Growth-Survival, Stature-Recruitment & 282 species \\
\hline
\end{tabular}

Fig. 2: Predicted and observed basal area in four model scenarios (Table 1). (A) Locations of species (colored dots) and representative plant functional types (PFTs) used for model scenarios (black dots) in demographic space; each species was assigned to a PFT based on proximity in demographic space and color-coded as in Fig. 1. (B) Predicted (lines) and observed (asterisks) basal area by PFT in old-growth tropical forest (BCI, black is total basal area) and (C) secondary tropical forest in the Barro Colorado Nature Monument. RSME is the root mean square error of prediction of total basal area, MASE is the mean absolute scaled error of PFTlevel predictions (11).

To compare the observed dynamics of the 50-ha old-growth plot in BCI with model predictions, we initialized the model with inventory data from 1985 and simulated forest dynamics until 2010. When only the growth-survival tradeoff was included, basal area was predicted to decline because of a decline of the number of trees $>20 \mathrm{~cm}$ diameter, especially of fast species (Figs. 2B, S1). Including the stature-recruitment tradeoff axis improved the match between predicted and observed basal area and aboveground biomass (AGB, Figs. 2B, S2-S3) for different PFTs and size classes (Figs. S4-S5). However, when all species were simulated individually (scenario 4$)$, the number of large trees (>60 cm diameter) and basal area were incorrectly predicted to increase (Fig. S1). This was due to the greater influence of measurement errors due to small sample sizes when parameterizing the model for 282 species (11), although most species-level predictions were reliable (Fig. S6). Maximum diameters were accurately predicted by all scenarios, except for scenario 2, where observed maximum diameters $>150 \mathrm{~cm}$ 
were not reproduced (Fig. S7). This test shows that the model scenarios that included both tradeoffs were able to reproduce the structure and stability of the forest over the time span that was used to derive demographic rates.

Next, we tested the ability of the model to predict successional changes in secondary forests. We used the same model parameterization scenarios, initialized the model with data from 40-year-old secondary forest, and compared predictions of forest dynamics with observations from a chronosequence of 60, 90, and 120-year-old secondary forests (two 1-ha plots in each age class). As in old-growth forest, predictions of secondary succession were most accurate when forest diversity was represented by 5 PFTs spanning both demographic tradeoffs. When only the growth-survival tradeoff was included, the increase of basal area (Fig. 2C) and AGB (Fig. S2) during succession was underestimated, because the number of large trees $(>60 \mathrm{~cm}$ diameter) was underestimated (Fig. S8). In contrast, when both tradeoffs were included, observed successional changes in basal area, AGB, and abundance for different PFTs and size classes were accurately reproduced (Figs. 2C, S2, S8-S10). However, when all species were simulated individually (scenario 4 ), the number of large trees ( $>60 \mathrm{~cm}$ diameter) and basal area of fast species and LLPs were overestimated. The observed peak in basal area in the 90 -year-old secondary forest is likely caused by remnant trees in the study plots and disappears when larger spatial scales are considered (16). The diameter distribution after 400 years of simulation closely matched the observed diameter distribution only when both demographic tradeoffs were included (Fig. 3A).

In addition to the above simulations, we also ran simulations with alternative initial conditions to explore the robustness of our results. The alternative initial conditions (bare-ground and 20-year-old forest; 11) did not qualitatively affect our results. For all initial conditions, the 5PFT case spanning both demographic tradeoffs yielded predictions that best matched observations (Fig. S11).

To assess whether the forest in the 50-ha plot at BCI is at equilibrium with the local disturbance regime, we simulated forest succession (starting from 40 years as above) under scenario 3 for 1000 years without any external disturbances. Here, the slow PFT and LLPs codominated the forest after 400-500 years (Fig. S12). Fast species died out because the canopy gaps that they require for persistence (17) are treated in our model in a simplistic (non-spatiallyexplicit) manner. In reality, however, the forest is comprised of a mosaic of patches of different successional age since the last disturbance event (18). Thus, we compared the simulated successional trajectories of the fast and slow PFTs with observed species composition at the 0.1ha scale to infer the patch-scale age distribution (Fig. S13, 11). This model-inferred age distribution suggests that the majority of the 0.1-ha patches within the BCI 50-ha plot are between 50 and 250 years old. This is consistent with LiDAR data collected on BCI, which suggest that between 0.43 and $1.6 \%$ of the area is disturbed every year, corresponding to an average disturbance interval between 63 and 233 years $(11,19)$. When we use the estimated proportion of 0.1 -ha patches in each age class to generate the PFT-composition at equilibrium with the disturbance regime, predictions closely match observations (Fig. 3B).

These results suggest that the forest in the 50-ha plot at BCI is at equilibrium with the local disturbance regime. This helps to resolve a long-standing dispute of whether long-lived pioneers are a transient feature of successional forests $(5,20,21)$ and shows that, in this forest, they are not transient, but an integral and dominant component of the old-growth forest. In fact, long-lived pioneers dominate most successional stages and contribute more AGB than any other demographic group, except in very young forests ( $<40$ years) or patches that have remained 
undisturbed for a long time (>400 years, Fig. S12). They are able to maintain populations in the absence of large-scale disturbances and compensate for their low recruitment by growing quickly up to the canopy or emergent layer where they may persist as seed source for several centuries $(8)$.

<INSERT FIG. 3>

Fig. 3: Model validation. (A) Diameter distribution in 400-year-old simulated forest for the four model scenarios. (B) Predicted and observed basal area in model scenario 3. Observed basal area is from an old-growth tropical forest in BCI, Panama. Predicted basal area is based on the estimated number of 0.1-ha patches in each age class (Fig. S13,11).

Overall, our results clearly show that two demographic tradeoffs are needed to accurately predict successional patterns in tropical forest structure and composition. Considering only the fast-slow continuum of life-histories is not sufficient, because it ignores long-lived pioneers, one of the most important (in terms of tree size and AGB) components in many tropical forests. Although the existence of long-lived pioneers has long been recognized (4), they have often been assumed to be part of the fast-slow continuum, i.e. considered to be mid-successional, because they reach their highest basal area in intermediate stages of succession (5). However, long-lived pioneers lie on a second demographic dimension $(8,22)$, and this second dimension is essential to understanding tropical forest dynamics.

Our results also suggest that a small number of demographic niches is sufficient to capture the dynamics of the BCI forest. Specifically, just 5 PFTs were sufficient to adequately capture successional patterns of forest composition and carbon dynamics (Figs. 2-3). To explore the robustness of the 5-PFT approach under future climate, we used relationships between climate, functional traits, and demographic rates to implement our model simulations under alternative future climate scenarios (11). As under current conditions, the 5-PFT and specieslevel models yielded similar predictions to each other under future climate scenarios (Fig. S14), suggesting that a limited number of PFTs may be sufficient to capture the community response to climate change. This conclusion warrants further investigation with models that include physiological mechanisms not included in our model, as well as additional functional axes (e.g., drought tolerance) that are likely to be relevant at broader spatial or temporal scales. Nevertheless, our results suggest that functional diversity in species-rich tropical forests may be much smaller than taxonomic diversity, and that tropical forest diversity could be accurately represented in Earth System Models by a small number of PFTs that span the relevant functional 35 axes (23).

Beyond suggesting a simple yet accurate means to represent tropical forest functional diversity with a limited number of PFTs, our study also demonstrates the feasibility of embracing species-level diversity. Together, the demographic forest model and the empirical demographic tradeoffs define an objective and reproducible workflow that also delivers stable predictions of forest dynamics when run at the species level. Such workflows, along with the increasing availability of tropical forest inventory data, offer the opportunity to develop truly species-based models to support the evidence-based planning of forest restoration and sustainable tropical forest management by predicting rates and trajectories of forest regrowth both at the species and community level (3). 


\section{References and Notes:}

1. Food and Agriculture Organization of the United Nations. Global Forest Resources Assessment. FAO Forestry Paper 163 (FAO, 2010).

2. S. P. Hubbell et al., Science 283, 554-557 (1999).

3. E. Rutishauser et al., Curr. Biol. 25, R787-R788 (2015).

4. R. L. Chazdon, Second Growth: The promise of tropical forest regeneration in an age of deforestation (The University of Chicago Press, Chicago, 2014).

5. B. Finegan, Trends Ecol. Evol. 11, 119-124 (1996).

6. P. B. Reich, J. Ecol. 102, 275-301 (2014).

7. T. Kohyama, E. Suzuki, T. Partomihardjo, T. Yamada, T. Kubo, J. Ecol. 91, 797-806 (2003).

8. N. Rüger et al., Ecol. Lett. 21, 1075-1084 (2018).

9. N. Strigul, D. Pristinski, D. Purves, J. Dushoff, S. Pacala, Ecol. Monogr. 78, 523-545 (2008).

10. D. W. Purves, J. W. Lichstein, N. Strigul, S. W. Pacala, Proc. Natl. Acad. Sci. U.S.A. 105, 17018-17022 (2008).

11. Materials and methods are available as supplementary materials on Science Online.

12. R. Condit, Tropical Forest Census Plots (Springer-Verlag, Berlin, Germany, and R. G. Landes Company, Georgetown, TX, 1998).

13. S. Bohlman, S. Pacala, J. Ecol. 100, 508-518 (2012).

14. L. Delchambre, Mon. Not. R. Astron. Soc. 446, 3545-3555 (2014).

15. J. S. Denslow, S. Guzman, J. Veg. Sci. 11, 201-212 (2000).

16. J. Mascaro, G. P. Asner, D. H. Dent, S. J. DeWalt, J. S. Denslow, For. Ecol. Manage. 276, 62-70 (2012).

17. M. D. Swaine, T. C. Whitmore, Vegetatio 75, 81-86 (1988).

18. J. Q. Chambers et al., Proc. Natl. Acad. Sci. U.S.A. 110, 3949-3954 (2013).

19. E. Lobo, J. W. Dalling, Proc. R. Soc. London Ser. B 281, 20133218 (2014).

20. R. Condit, R. Sukumar, S. P. Hubbell, R. B. Forster, Am. Nat. 152, 495-509 (1998).

21. D. Sheil, D. F. R. P. Burslem, Trends Ecol. Evol. 18, 18-26 (2003).

22. I. M. Turner, The Ecology of Trees in the Tropical Rain Forest (Cambridge University Press, Cambridge, 2001).

23. D. W. Purves, S. W. Pacala, Science 320, 1452-1453 (2008).

Acknowledgments: We thank Drew Purves for sharing the PPA model code, Alessandro Gentile 
Purves for inspiring discussions and helpful suggestions; Funding: N.R. was funded by a research grant from Deutsche Forschungsgemeinschaft DFG (RU 1536/3-1). N.R. and C.W. acknowledge the support of the German Centre for Integrative Biodiversity Research (iDiv) funded by Deutsche Forschungsgemeinschaft DFG (FZT 118). The BCI forest dynamics research project was founded by S. P. Hubbell and R. B. Foster and is now managed by R. Condit, S. Lao, and R. Perez under the Center for Tropical Forest Science and Smithsonian Tropical Research Institute in Panama. Numerous organizations have provided funding, principally the U.S. National Science Foundation, and hundreds of field workers have contributed.; The secondary forest data collection was funded by a grant from SENACYT (COL10-052) to D.D., S.D. and O.L. Author contributions: N.R. designed the research with input from C.F., J.L., and C.W.; N.R. and C.F. performed the research; R.C., D.D., S.D., S.H., and O.L. provided forest inventory data; N.R. wrote the manuscript with contributions from C.F., J.L., and C.W., and all authors contributed to subsequent versions of the paper. Competing interests: Authors declare no competing interests. Data and materials availability: The oldgrowth forest data are publicly available at https://doi.org/10.15146/5xcp-0d46. Secondary forest data will be made publicly available upon acceptance of the manuscript.

\section{Supplementary Materials:}

Materials and Methods

Figures S1-S15

Tables S1-S8

Data S1 to S2

Simulation code

References (24-39)

\section{References and Notes:}

1. Food and Agriculture Organization of the United Nations. Global Forest Resources Assessment. FAO Forestry Paper 163 (FAO, 2010).

2. S. P. Hubbell, R. B. Foster, S. T. O’Brien, K. E. Harms, R. Condit, B. Wechsler, S. J. Wright, S. Loo de Lao, Light-gap disturbances, recruitment limitation, and tree diversity in a Neotropical forest. Science 283, 554-557 (1999).

3. E. Rutishauser, B. Hérault, C. Baraloto, L. Blanc, L. Descroix, E. Doff Sotta, J. Ferreira, M. Kanashiro, L. Mazzei, M. V. N. d'Oliveira, L. C. de Oliveira, M. Peña-Claros, F. E. Putz, A. R. Ruschel, K. Rodney, A. Roopsind, A. Shenkin, K. E. da Silva, P. Sist, Rapid tree carbon stock recovery in managed Amazonian forests. Curr. Biol. 25, R787-R788 (2015).

4. R. L. Chazdon, Second Growth: The promise of tropical forest regeneration in an age of deforestation (The University of Chicago Press, Chicago, 2014).

5. B. Finegan, Pattern and process in neotropical secondary rain forests: The first 100 years of succession. Trends Ecol. Evol. 11, 119-124 (1996).

6. P. B. Reich, The world-wide "fast-slow" plant economics spectrum: a traits manifesto. $J$. Ecol. 102, 275-301 (2014). 
7. T. Kohyama, E. Suzuki, T. Partomihardjo, T. Yamada, T. Kubo, Tree species differentiation in growth, recruitment and allometry in relation to maximum height in a Bornean mixed dipterocarp forest. J. Ecol. 91, 797-806 (2003).

8. N. Rüger, L. S. Comita, R. Condit, D. Purves, B. Rosenbaum, M. D. Visser, S. J. Wright, C. Wirth, Beyond the fast-slow continuum: demographic dimensions structuring a tropical tree community. Ecol. Lett. 21, 1075-1084 (2018).

9. N. Strigul, D. Pristinski, D. Purves, J. Dushoff, S. Pacala, Scaling from trees to forests: Tractable macroscopic equations for forest dynamics. Ecol. Monogr. 78, 523-545 (2008).

10. D. W. Purves, J. W. Lichstein, N. Strigul, S. W. Pacala, Predicting and understanding forest dynamics using a simple tractable model. Proc. Natl. Acad. Sci. U.S.A. 105, 17018-17022 (2008).

11. Materials and methods are available as supplementary materials on Science Online.

12. R. Condit, Tropical Forest Census Plots (Springer-Verlag, Berlin, Germany, and R. G. Landes Company, Georgetown, TX, 1998).

13. S. Bohlman, S. Pacala, A forest structure model that determines crown layers and partitions growth and mortality rates for landscape-scale applications of tropical forests. J. Ecol. 100, 508-518 (2012).

14. L. Delchambre, Weighted principal component analysis: a weighted covariance eigendecomposition approach. Mon. Not. R. Astron. Soc. 446, 3545-3555 (2014).

15. J. S. Denslow, S. Guzman, Variation in stand structure, light and seedling abundance across a tropical moist forest chronosequence, Panama. J. Veg. Sci. 11, 201-212 (2000).

16. J. Mascaro, G. P. Asner, D. H. Dent, S. J. DeWalt, J. S. Denslow, Scale-dependence of aboveground carbon accumulation in secondary forests of Panama: A test of the intermediate peak hypothesis. For. Ecol. Manage. 276, 62-70 (2012).

17. M. D. Swaine, T. C. Whitmore, On the definition of ecological species groups in tropical rain forests. Vegetatio 75, 81-86 (1988).

18. J. Q. Chambers, I. Negron-Juarez, D. Magnabosco Marra, A. Di Vittorio, J. Tews, D. Roberts, G. H. Ribeiro, S. E. Trumbore, N. Higuchi, The steady-state mosaic of disturbance and succession across an old-growth Central Amazon forest landscape. Proc. Natl. Acad. Sci. U.S.A. 110, 3949-3954 (2013).

19. E. Lobo, J. W. Dalling, Spatial scale and sampling resolution affect measures of gap disturbance in a lowland tropical forest: implications for understanding forest regeneration and carbon storage. Proc. R. Soc. London Ser. B 281, 20133218 (2014).

20. R. Condit, R. Sukumar, S. P. Hubbell, R. B. Forster, Predicting population trends from size distributions: a direct test in a tropical tree community. Am. Nat. 152, 495-509 (1998).

21. D. Sheil, D. F. R. P. Burslem, Disturbing hypotheses in tropical forests. Trends Ecol. Evol. $18,18-26$ (2003).

22. I. M. Turner, The Ecology of Trees in the Tropical Rain Forest (Cambridge University Press, Cambridge, 2001). 
23. D. W. Purves, S. W. Pacala, Predictive models of forest dynamics. Science 320, 1452-1453 (2008).

24. I. Martínez Cano, H. C. Muller-Landau, S. J. Wright, S. A. Bohlman, S. W. Pacala, Tropical tree height and crown allometries for the Barro Colorado Nature Monument, Panama: a comparison of alternative hierarchical models incorporating interspecific variation in relation to life history traits. Biogeosciences 16, 847-862 (2019).

25. J. Chave, C. Andalo, S. Brown, M. A. Cairns, J. Q. Chambers, D. Eamus, H. Fölster, F. Fromard, N. Higuchi, T. Kira, J.-P. Lescure, B. W. Nelson, H. Ogawa, H. Puig, B. Riéra, T. Yamakura, Tree allometry and improved estimation of carbon stocks and balance in tropical forests. Oecologia 145, 87-99 (2005).

26. R. Condit, S. Lao, R. Pérez, S. B. Dolins, R. B. Foster, S. P. Hubbell, Barro Colorado Forest Census Plot Data, 2012 Version. Center for Tropical Forest Science Databases. (2012) DOI http://dx.doi.org/10.5479/data.bci.20130603.

27. R. S. Condit, S. Aguilar, R. Pérez, S. Lao, S. P. Hubbell, R. B. Foster, Barro Colorado 50-ha Plot Taxonomy 2017. Center for Tropical Forest Science Databases. (2017) DOI http://dx.doi.org/10.25570/stri/10088/32990.

28. R. S. Condit, S. Aguilar, R. Pérez, S. Lao, R. B. Foster, S. P. Hubbell, Complete data from the Barro Colorado 50-ha plot: 423617 trees, 35 years, v3, DataONE Dash, Dataset, (2019) DOI https://doi.org/10.15146/5xcp-0d46.

29. R. J. Hyndman, A. B. Koehler. Another look at measures of forecast accuracy. Int. J. Forecast. 22, 679-688 (2006).

30. R Development Core Team. (2019). R: a language and environment for statistical computing [WWW Document]. Available at: http://www.r-project.org. Last accessed 16 August 2019.

31. D. H. Dent, S. J. DeWalt, J. S. Denslow, Secondary forests of central Panama increase in similarity to old-growth forest over time in shade tolerance but not species composition. $J$. Veg. Sci. 24, 530-542 (2013).

32. I. L. Jones, S. J. DeWalt, O. R. Lopez, L. Bunnefeld, Z. Pattison, D. H. Dent, Above- and belowground carbon stocks are decoupled in secondary tropical forests and are positively related to forest age and soil nutrients respectively. Sci. Total Environ. 697:133987 (2019).

33. I. Šímová, C. Violle, J.-C. Svenning, J. Kattge, K. Engemann, B. Sandel, R. K. Peet, S. K. Wiser, B. Blonder, B. J. McGill, B. Boyle, N. Morueta-Holme, N. J. B. Kraft, P. M. van Bodegom, A. G. Gutiérrez, M. Bahn, W. A. Ozinga, A. Tószögyová, B. J. Enquist, Spatial patterns and climate relationships of major plant traits in the New World differ between woody and herbaceous species. J. Biogeogr. 45, 895-916 (2018).

34. D. N. Karger, O. Conrad, J. Böhner, T. Kawohl, H. Kreft, R. W. Soria-Auza, N. E. Zimmermann, H. P. Linder, M. Kessler, Climatologies at high resolution for the earth's land surface areas. Scientific Data 4:170122 (2017).

35. D. N. Karger, O. Conrad, J. Böhner, T. Kawohl, H. Kreft, R. W. Soria-Auza, N. E. Zimmermann, H. P. Linder, M. Kessler, Data from: Climatologies at high resolution for the earth's land surface areas. Dryad Digital Repository, (2017) DOI https://doi.org/10.5061/dryad.kd1d4. 
36. B. M. Sanderson, R. Knutti, P. Caldwell, Representative democracy to reduce iunterdependency in a multimodel ensemble. J. Clim. 28: 5171-5194 (2015).

37. G. R. Goldsmith et al., Plant-O-Matic: A dynamic and mobile guide to all plants of the Americas. Methods Ecol. Evol. 7, 960-965 (2016).

38. G. Baskerville, Use of logarithmic regression in the estimation of plant biomass. Can. J. For. Res. 2, 49-53 (1972).

39. M. Aubry-Kientz, V. Rossi, G. Cornu, F. Wagner, B. Hérault, Temperature rising would slow down tropical forest dynamic in the Guiana Shield. Sci. Rep. 9:10235 (2019). 


\section{Science MIAAAS}

\section{Supplementary Materials for}

Demographic tradeoffs predict tropical forest dynamics

N. Rüger,* R. Condit, D. H. Dent, S. J. DeWalt, S. P. Hubbell, J. Lichstein, O. R. Lopez, C. Wirth, C. E. Farrior

*Correspondence to: nadja.rueger@idiv.de

This PDF file includes:

Materials and Methods

Figs. S1 to S15

Tables S1 to S8

Captions for Data S1 to S2

Caption for Simulation code

References (24-39)

Other Supplementary Materials for this manuscript include the following:

Data $\mathrm{S} 1$ to $\mathrm{S} 2$

Simulation code 


\section{Materials and Methods}

The PPA model

We used a deterministic version of the PPA model that is based on Purves et al. (10), where tree crowns are assumed to be flat. The simulation area was 1 ha and the model time step was 5 years. The model works on cohorts of trees that share the same age, diameter at breast height $(\mathrm{dbh}$, in $\mathrm{cm}$ ) and species/plant functional type (PFT). The number of trees in a cohort can be fractions of individuals, including numbers $<1$. Cohorts are removed from the simulation when they have $<0.001$ individuals. We extended the model from two to four canopy layers (13) and species/PFTs are characterized by growth and mortality rates in each of the four layers. We modified several aspects of the model. Cohorts are removed if they are assigned to a layer $>4$. Sapling cohorts enter the model at $1 \mathrm{~cm}$ dbh (originally $0.01 \mathrm{~cm}$ ). Recruitment rates are constant (see below, originally they scaled with a species' crown area in the canopy layer). Sapling cohorts recruit to layer 4 . The $\mathrm{dbh}(\mathrm{cm})$-crown radius $(\mathrm{m})$ relationship is nonlinear (originally linear),

$$
\text { crown radius }=0.5 * \mathrm{dbh}^{0.62} \text {. }
$$

Likewise, the dbh $(\mathrm{cm})$-height $(\mathrm{m})$ relationship is non-linear and parameters for both allometries were determined using data from BCI (24),

$$
\text { height }=11^{*}(\mathrm{dbh} / 10)^{0.5} \text {. }
$$

As a single allometry for all trees worked equally well as species-specific allometries in determining structural and dynamics properties of the forest (13), we used a single allometry for crown radius and height.

To calculate aboveground biomass (AGB, Mg), we followed ForestGEO protocols and used allometric equations based only on dbh and wood density (wd), but not height, from Chave et al. (25) for moist tropical forest:

$\mathrm{AGB}=\left(\mathrm{wd}^{*} \exp \left(-1.499+2.148 * \log (\mathrm{dbh})+0.207 * \log (\mathrm{dbh})^{2}-0.0281 * \log (\mathrm{dbh})^{3}\right) / 1000\right)$, where $\mathrm{dbh}$ is measured in $\mathrm{cm}$ and $\mathrm{wd}$ in $\mathrm{g} / \mathrm{cm}^{3}$.

\section{Parameterization}

In a previous study, we performed a weighted PCA (14) on nine demographic parameters for 282 species from the BCI 50-ha plot, namely growth rate in the four canopy layers, survival (expressed as lifespan) in the four canopy layers, and the number of recruits per unit of adult basal area, which were derived from forest inventory data $(8,26)$. We follow the taxonomy as of 2017 (27). The first two principal components of this PCA correspond to the fast-slow continuum (37\% explained variation) and a stature-recruitment tradeoff ( $28 \%$ explained variation), respectively. Here we used a slightly modified version of the PCA using the number of recruits per unit of total species' basal area, and used the first two principal components (henceforth 'axes' or 'tradeoffs') to determine model parameters. An exception are recruitment rates, which we determined directly from forest inventory data (independent of the basal area of a species and independent from the PCA). We assumed recruitment rates to be constant over time because the 50-ha plot is embedded within a larger forest area from which seeds continuously arrive into the study area. Moreover, relationships between recruitment rates per PFT and total basal area in $31.25 \times 31.25 \mathrm{~m}^{2}$ subplots or basal area of the respective PFT were weak or absent (not shown).

To determine growth and mortality rates, we specified coordinates of five PFTs symmetrically in the two-dimensional demographic space (Fig. 1 in main manuscript): 
- Intermediate (location $\mathrm{x}_{1}=0, \mathrm{x}_{2}=0$ )

- Fast (location $\mathrm{x}_{1}=-1.5, \mathrm{x}_{2}=0$ )

- Slow (location $\mathrm{x}_{1}=1.5, \mathrm{x}_{2}=0$ )

- Long-lived pioneer (LLP, location $\mathrm{x}_{1}=0, \mathrm{x}_{2}=1.5$ )

- Short-lived breeder (SLB, location $\mathrm{x}_{1}=0, \mathrm{x}_{2}=-1.5$ )

Coordinates of $+/-1.5$ on the two tradeoff axes correspond to between 9 and $19 \%$ of species having more extreme demographic strategies.

For the simulations including all species, we used their PCA scores along the $1^{\text {st }}$ or $1^{\text {st }}$ and $2^{\text {nd }}$ PCA tradeoff axis, depending on the scenario (Data S1).

We then solved the linear system of equations consisting of the PCA loadings of the nine parameters (Table S1) and species' scores (setting all species' scores on axes 3 to 9 to 0, i.e. $\mathrm{x}_{3} \ldots \mathrm{x}_{9}=0$ ) to obtain transformed input parameters to the PCA (Data S1). These were then backtransformed to model parameters by de-centering, de-scaling, and de-logging. Lifespan was transformed into mortality, i.e. mortality $=1 /$ lifespan $($ Tables S2,S3).

From these strategies, we simulated four scenarios, differing in the number of species/PFTs:

1. 1 tradeoff, 3 PFTs (fast, intermediate, slow)

2. 1 tradeoff, 282 species

3. 2 tradeoffs, 5 PFTs (slow, fast, LLP, SLB, intermediate)

4. 2 tradeoffs, 282 species

Annual recruitment rates (at $1 \mathrm{~cm} \mathrm{dbh}$ ) for each PFT were determined as the average annual sum of recruits (per ha) of species that were assigned to the PFT. For scenarios (2) and (4), species without observed recruits ( 25 species) were assigned one recruit in 25 years and 50 ha, i.e. 0.0008 recruits per year and ha. New recruits enter the simulation every year and experience deterministic mortality every year. However, annual recruit numbers were determined from 5year census intervals. Thus, we adjusted annual recruit numbers by species/PFT-specific mortality such that, after a 5-year time step, simulated recruit numbers matched observed average recruit numbers in 5-year census intervals in the 50-ha plot at BCI.

Wood density (wd) for PFTs was determined as the volume-weighted mean of wd in oldgrowth forest. Wood density is from bci.spptable (28; sometimes to genus or family level only). Individual tree volume was calculated as volume $=\exp \left(-1.499+2.148 * \log (\mathrm{dbh})+0.207 * \log (\mathrm{dbh})^{2}-0.0281 * \log (\mathrm{dbh})^{3}\right) / 1000$.

Volume-weighted wood density of the PFTs in secondary forest was slightly different from that of the PFTs in the old-growth forest, due to differences in species' abundance. We used the volume-weighted wood density of the PFTs in old-growth forest, when we calculated AGB in simulations of old-growth forest dynamics, and wood density of the PFTs in secondary forest plots, when we calculated AGB in simulations of secondary forest succession.

Species assignment to PFTs, model initialization and validation Old-growth forest - In the 50-ha permanent plot in tropical moist forest on Barro Colorado Island (BCI), Panama, every tree $\geq 1 \mathrm{~cm}$ dbh is tagged, mapped, and measured approximately every five years (26). In this paper our analyses are based on six censuses (conducted between 1985 and 2010). We leave out the first census of 1982 because in this census some tall trees with buttresses were measured at lower heights than in subsequent censuses introducing a bias in basal area and AGB estimates. Detailed methods for the plot censuses can be found in (2) and (12). 
For comparison of model predictions with data, we assigned species to PFTs based on their PCA scores along the $1^{\text {st }}$ or $1^{\text {st }}$ and $2^{\text {nd }}$ PCA axis. For scenarios (1) and (3), we assigned species to the PFT with the closest location that was used for parameterization (Figs. 1, 2A in main manuscript). For scenario (1), 98 species were assigned to the 'fast' PFT, 83 to the 'slow' PFT, and 101 to the 'intermediate' PFT. For scenario (3), 75 species were assigned to the 'fast' PFT, 76 to the 'LLP' PFT, 60 to the 'slow' PFT, 30 to the 'SLB' PFT, and 41 to the 'intermediate' PFT. For visualization purposes, we used the same PFT assignments for scenarios (2) and (4), where all species were simulated individually.

For simulation of old-growth forest dynamics, we initialized the model with the average (in terms of species abundances and tree sizes) of the 50-ha plot on Barro Colorado Island in 1985. Individuals of species that were not included in the PCA (mostly palms and hemiepiphytes, $1.4 \%$ of individuals, $3.5 \%$ of basal area) were omitted in these calculations as they could not be associated with a PFT. Thus, the initial state of the model is slightly less populated than the real forest. Species were assigned to one of 111 size classes and tree numbers were aggregated by size class and species/PFT. Size classes were $1 \mathrm{~cm}$ wide for individuals between 1 and $50 \mathrm{~cm}$ $\mathrm{dbh}, 2 \mathrm{~cm}$ wide for individuals between 50 and $100 \mathrm{~cm} \mathrm{dbh}$, and $5 \mathrm{~cm}$ wide for larger individuals. The lower limit of the size class was used as initial cohort size in the PPA model.

We validated the model against field data in terms of overall basal area, AGB, and abundance per PFT, as well as in different size classes. Forest structure and composition was determined from the six censuses of the 50-ha plot (1985-2010). Basal area and AGB were compared for the size classes $1-20 \mathrm{~cm}, 20-60 \mathrm{~cm}, \geq 60 \mathrm{~cm}, \geq 1 \mathrm{~cm}$ dbh (total). Abundance was compared for the size classes $5-20 \mathrm{~cm}, 20-60 \mathrm{~cm}, \geq 60 \mathrm{~cm}, \geq 5 \mathrm{~cm}$ dbh (total).

As measures of predictive power, we calculated the root mean square error (RMSE) of prediction for total basal area. RMSE measures the average deviation of the predicted value from the observed value and is in the same unit as observations $\left(\mathrm{m}^{2} / \mathrm{ha}\right)$. We also calculated the mean absolute scaled error (MASE) to compare the predictive power of different model parameterizations at the PFT level that are at different scales (29). MASE is scale-independent and measures the predictive power of a model relative to a naïve random walk forecast.

We compared simulated (after 100 years of simulation) and observed maximum diameters. Maximum diameter for each PFT in the field data and the simulations was calculated as the largest 5-cm diameter class with $>0.1$ individuals per ha. For parameterizations (2) and (4) (282 species), it was calculated for each species as the largest 5 -cm diameter class with $>0.005$ individuals per ha.

We compared the diameter distribution of simulated 400-year-old forest with the observed diameter distribution of the old-growth forest. The observed diameter distribution again is an average of six censuses and includes palms and hemiepiphytes. All analyses were carried out in $\mathrm{R}(30)$.

Secondary forest - Data on secondary forests is from eight forest plots (1 ha each) in the Barro Colorado Nature Monument National Park, all plots are $<7 \mathrm{~km}$ away from the old-growth forest plot (15, 31-32). There were two plots in each of four age classes (40, 60, 90, and 120 years). All secondary forest stands had been in agriculture, including pasture, swidden farming, and plantation farming, for undetermined lengths of time prior to fallow (15). The plots were inventoried between 2011 and 2014. In all plots, every tree $\geq 5 \mathrm{~cm}$ dbh was tagged, mapped, and measured, and in most of the plots, in a 0.5 -ha subset of the plot every tree $\geq 1 \mathrm{~cm}$ dbh was 
tagged, mapped, and measured. We only considered the largest stem of multi-stemmed individuals to match old-growth forest data.

We excluded 254 individuals without recorded dbh as well as palms (8 species, 474 individuals), hemiepiphytes ( 1 species, 4 individuals), cultivated species ( 1 species, 1 individual), and unidentified individuals (214). Of the remaining 242 species (9935 individuals), we had no information on demographic strategy from the old-growth forest for 50 species (1212 individuals). We assigned some of these species to the PFTs of a closely related species, and others based on average demographic characteristics of taxonomically-related species and/or species with similar functional traits, i.e. wood density and growth form (Data S2). Wood density and growth form is from bci.spptable (28; sometimes to genus or family level only).

For simulation of secondary forest succession, we initiated the model with the average of two 1-ha 40-year old secondary forest plots. Species were assigned to one of 111 size classes and tree numbers were aggregated by size class and PFT. Size classes were $1 \mathrm{~cm}$ wide for individuals between 1 and $50 \mathrm{~cm} \mathrm{dbh}, 2 \mathrm{~cm}$ wide for individuals between 50 and $100 \mathrm{~cm} \mathrm{dbh}$, and $5 \mathrm{~cm}$ wide for larger individuals. The lower limit of the size class was used as initial cohort size in the PPA model.

We validated the model against field data in terms of total basal area, AGB, and abundance per PFT, as well as in different size classes. Basal area, AGB, and abundance were compared for the size classes $5-20 \mathrm{~cm}, 20-60 \mathrm{~cm}, \geq 60 \mathrm{~cm}, \geq 5 \mathrm{~cm}$ dbh (total), because sampling of the different secondary forest plots $<5 \mathrm{~cm}$ dbh was inconsistent. Observed AGB was calculated using the same PFT-level wood density as in the respective model scenario. As a result, total observed biomass varies slightly between the different model scenarios. To calculate RSME and MASE, we averaged the observations in the two 1-ha plots per age class to yield a single time series of basal area.

Comparison of PFT-level and species-level simulations

For the old-growth forest, the species-based simulation including two tradeoffs (scenario 4) performed slightly worse than the PFT-based simulation (scenario 3) and slightly overestimated the basal area of fast species, slow species, and LLPs. The reason is that growth rates in the top (and second) canopy layer were overestimated and/or mortality rates in the top canopy layer were underestimated for some species (e.g. for Cecropia insignis (fast), Hybanthus prunifolius (slow), Poulsenia armata (fast), Quararibea asterolepis (LLP), Trichilia tuberculata (slow)). This can occur because species have different sample sizes in the different canopy layers. As an example, $C$. insignis has few individuals in the lowest canopy layer 4 , while $H$. prunifolius has few individuals in the top canopy layer. Thus, the demographic rates in different layers are associated with different levels of uncertainty, which affects species positions in the PCA space, and hence parameters estimates.

For the secondary forest plots, most of the discrepancy between observed and simulated basal area is due to the fact that species composition and especially species abundances varied strongly between the different plots. The model was initialized with the species composition and abundance of the two 40-year-old plots, but simulation results were validated against data from different plots. Additionally, single species that were rare in the old-growth forest (used to derive demographic rates), were affected by the same sample size issue mentioned above. Examples are Apeiba tibourbou (fast), Cordia alliodora (fast), Lacmellea panamensis (LLP), Pachira sessilis (LLP), Terminalia amazonia (LLP), and Xylopia macrantha (LLP), for which growth rates in single layers were overestimated. For Apeiba tibourbou, mortality was additionally 
underestimated. All of these species were especially abundant in the 40 -year-old plots. Thus, the combination of idiosyncrasies in species composition and unrealistic parameter estimates leads to the inferior performance of the species-based approach. The PFT-based approach, in contrast, averages over species composition as well as demographic rates and delivers accurate predictions of 'average forest succession'.

Simulation of early successional dynamics

We took two approaches to assess model behavior during early succession ( $<40$ years). First, we derived recruitment rates in high-light conditions (gaps) and simulated forest succession from bare ground. Second, we initialized the model with sparser data from 20 -year-old secondary forests and simulated forest recovery as in the main text.

Gap-dependent recruitment rates - To estimate recruitment rates of species in very early successional forests from the old-growth forest data, we found the recruitment rates of species in areas of the forest that appear to be open canopy gaps. To find gaps within the old-growth forest data, we took subplots of 5 meter radius, spaced every 4 meters. If the total estimated crown area of the trees rooted within the 5 meter radius plots was less than the area of the plot, we called the center 4 meter radius of the subplot a "gap". Using these gap-specific recruitment rates for the first 25 years (and the average rates from old-growth forest subsequently), we simulated forest recovery from bare ground and compared it with the data from secondary forests starting at 40 years. Here, as in the main text, scenario 3 (5 PFTs) reproduced the dynamics of the data most accurately (Fig. S11A). In scenario 1 (3 PFTs), the recovery of fast species was underestimated, while the recovery of slow species was overestimated. In scenario 2 (1 tradeoff -282 species), the recovery of slow species was underestimated. In scenario 3 (5 PFTs), fast species decreased too late, LLPs increased too slowly, and intermediate species had too much basal area. The overall recovery of basal area was too slow. Scenario 4 (2 tradeoffs - 282 species) deviated most strongly from observed forest recovery.

Initialization at 20 years - We used data from 0.48 ha of 20 -year-old forests on trees $\geq 5 \mathrm{~cm}$ dbh (15) to initialize the model. As there was no information on small trees available, we used the data from the 40-year-old forest for the small size classes $(1-5 \mathrm{~cm}$ dbh). We also excluded trees with a dbh $>40 \mathrm{~cm}$, because we assumed that those were remnant trees. Again, scenario 3 (5 PFTs) reproduced observed forest recovery best (Fig. S11B). The scenarios only including only one tradeoff underestimate forest recovery, while scenario 4 ( 2 tradeoffs -282 species) considerably overestimated forest recovery.

Both analyses do not change the qualitative results of the main text. However, the simulations beginning at 40 years better adhere to the strengths and limitations of our approach. This is because our model parameterization exclusively relies on the demographic rates of species in old-growth forest. However, the average recruitment rates of species in old-growth forests are likely greatly underestimating recruitment rates in very early successional stages, especially for early successional species. Moreover, starting from 'bare ground' in central Panama means starting from cattle pastures which are covered in dense grass and burn regularly. Seed characteristics of tree species germinating in the face of strong competition with grasses and regular fires, and traits of saplings that survive fires are outside the range of traits of species that occur in the 50-ha plot. Thus, very young secondary forests are, to a large degree, composed of 
species that are never or very rarely found in older forests and that also represent different demographic strategies. These factors make it difficult to extend the model to very early successional forests without specific research on the demographic tradeoffs they exhibit and data on their dynamics.

\section{Disturbance interval}

Analyses from detailed LiDAR data from the year 2009 estimated $0.43 \%$ of the area of BCI to be canopy gaps with $<2 \mathrm{~m}$ canopy height and $1.6 \%$ of the area to be canopy gaps $<5 \mathrm{~m}$ canopy height (19). Assuming that the vegetation can re-grow to a canopy height between 2 and $5 \mathrm{~m}$ within one year, the fraction of the forest that is disturbed every year is between 0.43 and $1.6 \%$. This corresponds to an average disturbance interval between $62.5(100 / 1.6)$ and $232.6(100 / 0.43)$ years.

Age distribution and simulated equilibrium forest

We divided inventory data from the six censuses between 1985 and 2010 from the 50-ha plot into $51231.25 \mathrm{~m} \times 31.25 \mathrm{~m}$ subplots and calculated the basal area $\left(\mathrm{m}^{2} / \mathrm{ha}\right)$ of species assigned to the slow and fast PFTs of scenario 3 for each subplot. Then, we determined the year (in steps of 5 years) in a simulated succession to which the basal area of fast and slow PFTs in each subplot was most similar, respectively, and took their mean. As the model was initialized with inventory data from 40-year-old forest, we linearly extrapolated the basal area of PFTs for younger ages between $0 \mathrm{~m}^{2} /$ ha for year 0 and the observed basal area at year 40 . The resulting combined (across censuses) age distribution of subplots (Fig. S13) was then used to generate a 'simulated' equilibrium of the forest as the sum of simulated basal area or AGB of the respective ages, weighted by the proportion of subplots in the respective age class. Note: We only considered the fast and slow PFTs because they show a clear successional pattern, while LLPs maintain high and SLBs and the intermediate PFT maintain low basal area throughout much of the succession.

Simulation of forest dynamics under different climate scenarios

To evaluate forest dynamics under different future climate scenarios, we first determined projected climate variables for the year 2070 under two representative concentration pathways (RCP2.6 and RCP8.5), we then assessed the projected change in functional traits using established climate-trait relationships (33), and finally derived changes in demographic rates using trait-demography relationships $(8)$.

Climate scenarios - We downloaded reference climate data (1979-2013) as well as climate projections (CMIP5) for 2070 (2061-2080) under RCP2.6 and RCP8.5 from CHELSA for the coordinates of BCI (lat 9.1543, lon -79.8461, 34-35). We selected ten climate models with low interdependency (CanESM2, CESM1-CAM5, CNRM-CM5, CSIRO-Mk3-6-0, GFDL-ESM2G, GISS-E2-H, HadGEM2-AO, IPSL-CM5A-LR, MPI-ESM-MR, NorESM1-M; 36). We then determined the mean of predicted mean annual temperature $\left({ }^{\circ} \mathrm{C} * 10\right)$, annual precipitation $\left(\mathrm{kg} / \mathrm{m}^{2}\right)$, and temperature seasonality (standard deviation of monthly temperature, ${ }^{\circ} \mathrm{C} * 100$ ) and precipitation seasonality (coefficient of variation of monthly precipitation, $\mathrm{kg} / \mathrm{m}^{2}$ ) across the ten models (Fig. S15, Table S4). The aridity index and solar radiation were not available for climate projections. The ten models consistently predicted increasing temperatures for the year 2070 . Projected changes in other climatic variables were more variable and rather moderate. Rainfall, temperature seasonality, and rainfall seasonality were predicted to slightly increase on average. 
Projected changes in functional traits - We used data from Š́mova et al. (33) to determine climate-traits relationships for three functional traits that are strongly related to the demographic rates of tree species at BCI (8), namely adult height (m, mean, SD), seed mass (mg, mean), and wood density $\left(\mathrm{g} / \mathrm{cm}^{3}\right.$, mean, SD). We fit linear models of grid-cell means and SDs of traits versus mean annual temperature (T), annual rainfall (P), and temperature (TS) and rainfall seasonality (PS), all of them in linear and quadratic form. Trait means and SDs were determined based on range maps for 88,417 New World species (37). From the 877 grid cells, we excluded nontropical climates and extremely seasonal climates to maximize the applicability of modeled relationships to BCI. We selected 187 grid cells with T>240 and TS $<1000$. We identified the most parsimonious models (based on AICc) using the dredge function in the 'MuMIn' package in R (Table S5). From these models, we predicted functional traits under the reference and future climate scenarios (Table S6). Consistent with continent-wide climate-trait relationships (33), mean height, seed mass and wood density were predicted to increase, while the SDs of height and wood density were predicted to decrease (Table S6). All changes in functional traits were more severe for RCP8.5 than RCP2.6.

Projected changes in demographic rates - Demographic rates and spectra show strong relationships with functional traits and trait spectra (8). Specifically, the fast-slow continuum (x) is aligned with wood density, while the stature-recruitment tradeoff $(y)$ is aligned with plant height. Both demographic dimensions are related to seed mass (Fig. 3a in 8). We applied projected changes in traits to predict functional traits under the two climate scenarios at BCI (Table S7). To project changes in demographic rates, we then fitted linear models for species' $\mathrm{x}$ and y positions in the two-dimensional demographic space, using wood density (WD), log maximum height, and $\log$ seed mass $\left(\mathrm{R}^{2}(\mathrm{x})=0.47, \mathrm{R}^{2}(\mathrm{y})=0.50\right)$. As wood density is normally distributed at BCI, we transformed predicted mean log WD into mean WD by accounting for the variance of wood density (mean WD $=\exp \left(\right.$ mean $\left.\left.\log \mathrm{WD}+0.279^{2}\right), 38\right)$.

Life-history strategies at BCI are predicted to shift towards slower strategies and also slightly towards more 'long-lived pioneerness' (i.e. towards more positive values along the xand y-dimensions of the demographic strategy space; Table S8). As standard deviations of log height and log wood density are predicted to decrease, and as these two traits are strongly aligned with the two demographic dimensions, we would also expect the variation of demographic strategies along both dimensions to decrease. To derive species' positions in demographic space under altered climate, we first adjusted the SD of demographic strategies by multiplying species' original $x$ values by $0.130 / 0.138=0.942(\mathrm{RCP} 2.6)$, and $0.110 / 0.138=0.797$ (RCP8.5), y values by 0.66/0.74 $=0.892$ (RCP2.6), and 0.52/0.74 =0.703 (RCP8.5). Note: As wood density is normally distributed at BCI, we applied the projected change in the SD of log WD to the SD of WD instead. We then shifted species' positions by +0.140 (RCP2.6) and +0.322 (RCP8.5) along the $\mathrm{x}$-axis, and by +0.024 (RCP2.6) and +0.089 (RCP8.5) along the $\mathrm{y}-$ axis.

Simulation of forest dynamics under different climate scenarios - We used the shifted positions in demographic space to derive updated parameter values and to assign species to the PFTs. We used the new PFT assignments to calculate recruitment rates per PFT in the same way as for the original model. We then predicted forest recovery under both climate scenarios (Fig. S14). For 
the model scenarios only including one demographic tradeoff (scenarios 1 and 2), predicted forest recovery hardly changed. However, for the model scenarios including both tradeoffs (scenarios 3 and 4), the rate of forest recovery was predicted to slow down with changing climate (cf. 39). This is mostly due to the predicted strong contraction of the demographic space along the second dimension, i.e. the stature-recruitment tradeoff. This contraction outweighs the shift towards more 'long-lived-pioneerness'. As a consequence, the most extreme long-lived pioneers (which attain the largest statures) are predicted to be lost, and the LLP PFT is predicted to be less 'long-lived-pioneery'. 

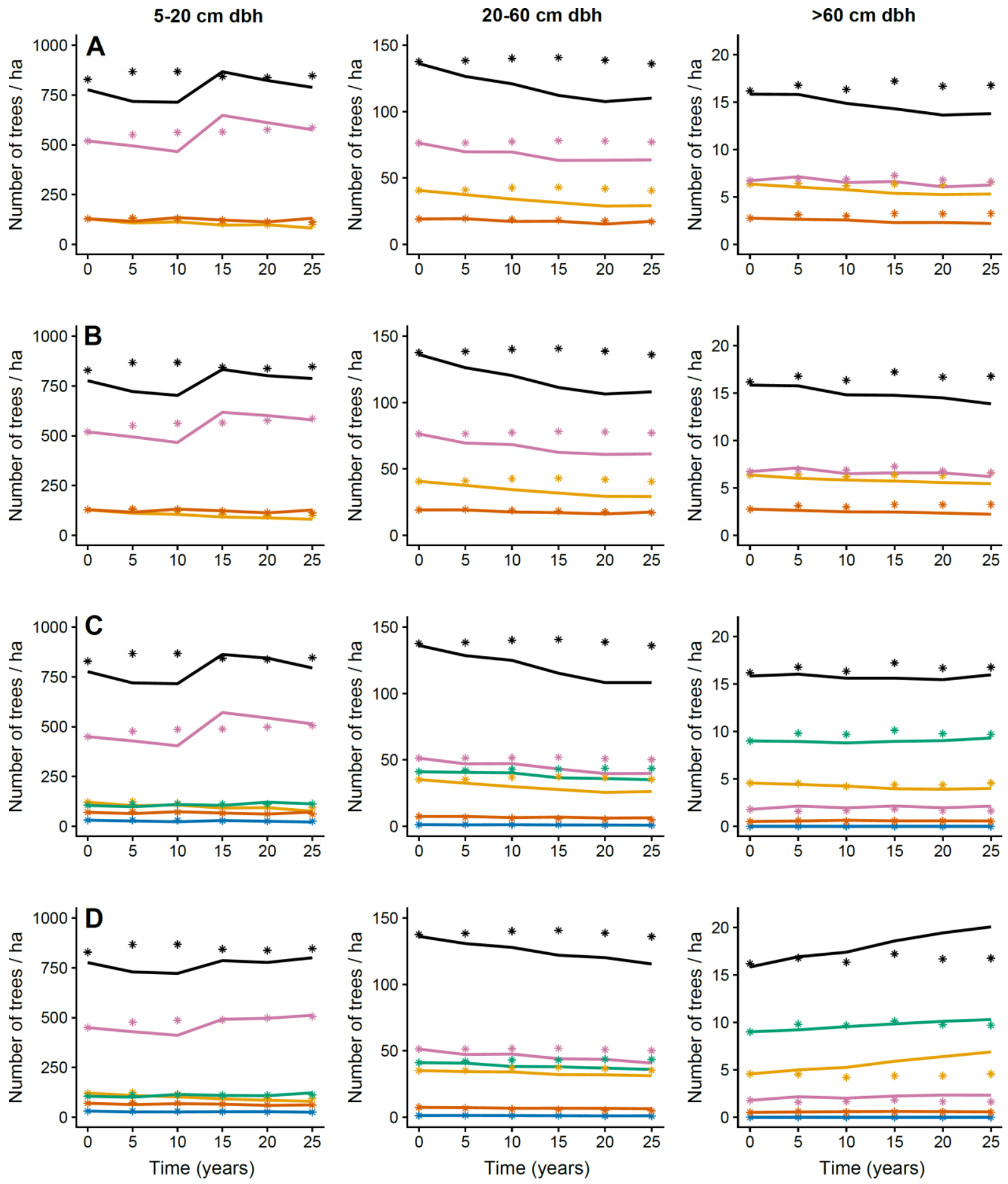

Fig. S1.

Predicted and observed abundance in four model scenarios (rows; A: 1 tradeoff -3 PFTs, B: 1 tradeoff -282 species, C: 2 tradeoffs - 5 PFTs, D: 2 tradeoffs -282 species) and three size classes (columns). Simulated (lines) and observed (asterisks) abundance by PFT in an oldgrowth tropical forest in Barro Colorado Island, Panama. Color code: purple - slow, yellow fast, green - LLP, blue - SLB, red - intermediate, black - total. 

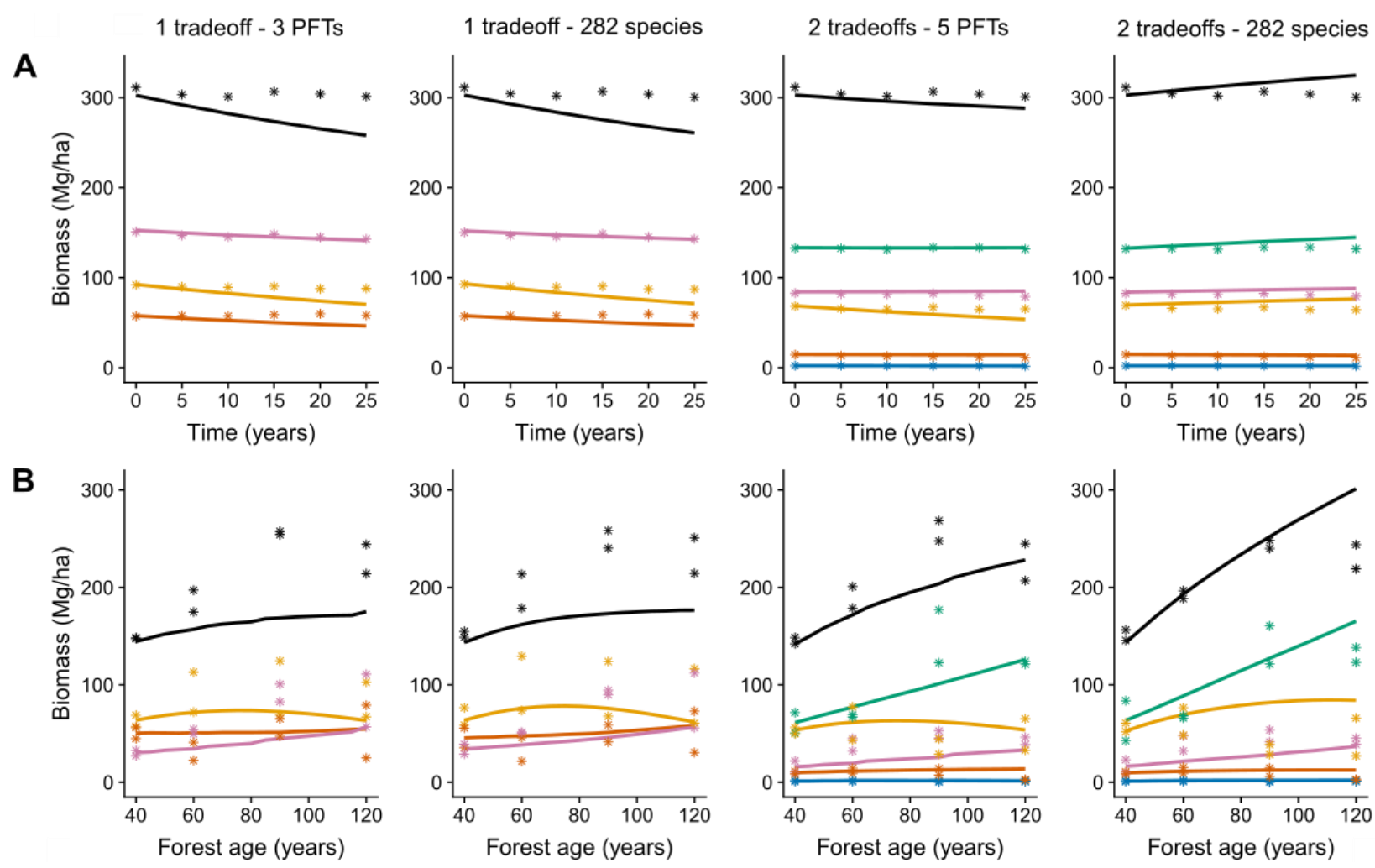

\section{Fig. S2.}

Predicted and observed aboveground biomass (AGB) in four model scenarios that differ in the number and demographic characteristics of simulated species or PFTs. (A) Predicted (lines) and observed (asterisks) AGB by PFT in an old-growth tropical forest (BCI, $\geq 1 \mathrm{~cm} \mathrm{dbh}$ ) and (B) in secondary tropical forest ( $\geq 5 \mathrm{~cm} \mathrm{dbh}$ ). Color code: purple - slow, yellow - fast, green - LLP, blue - SLB, red - intermediate, black - total. 

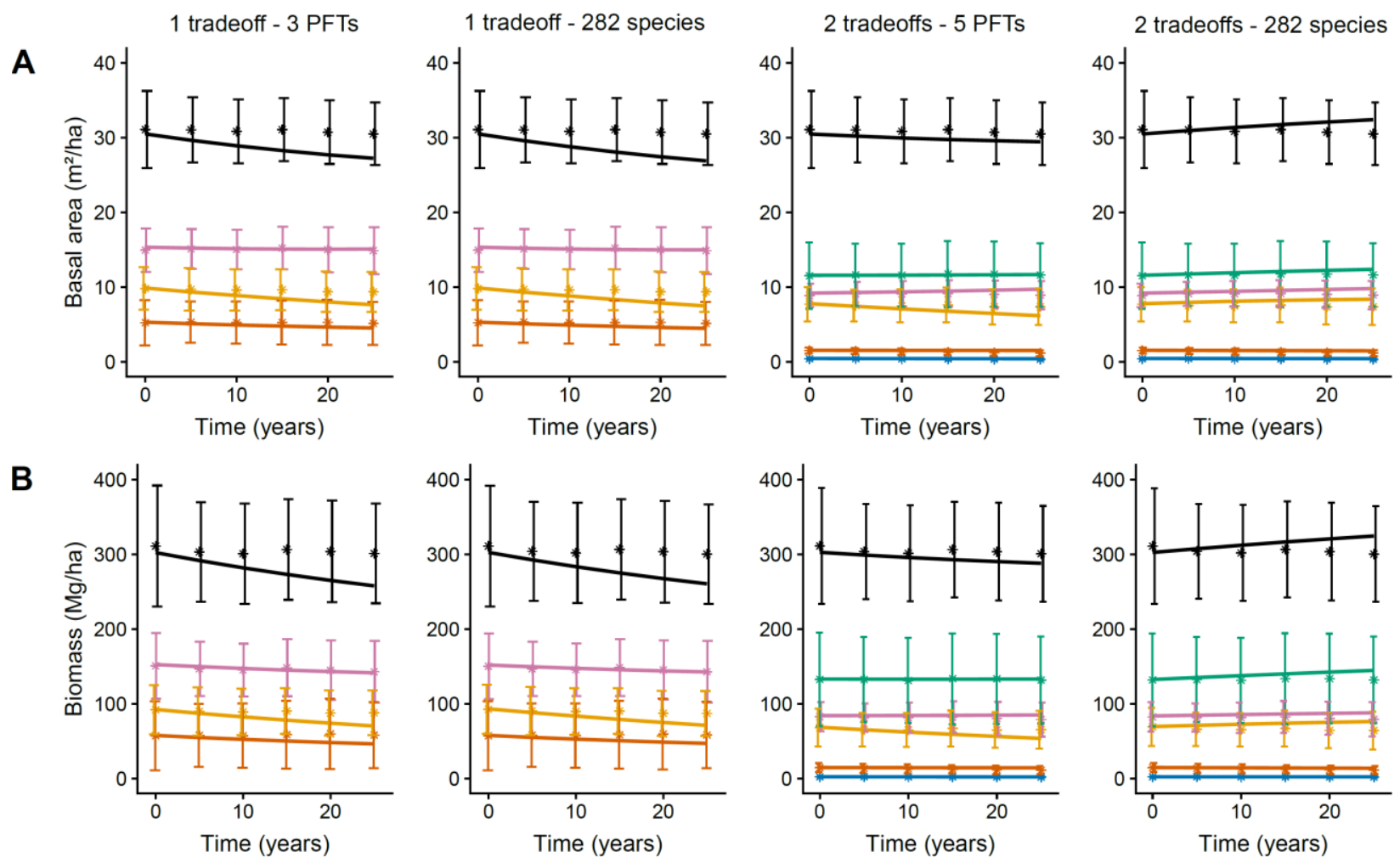

\section{Fig. S3.}

Predicted and observed (A) basal area and (B) aboveground biomass (AGB) in four model scenarios that differ in the number and demographic characteristics of simulated species or PFTs. Error bars show spatial variation (+/- 1SD) of basal area and AGB at the 1-ha scale in an oldgrowth tropical forest (BCI, $\geq 1 \mathrm{~cm}$ dbh). Lines show model predictions. Color code: purple slow, yellow - fast, green - LLP, blue - SLB, red - intermediate, black - total. 
$1-20 \mathrm{~cm} \mathrm{dbh}$
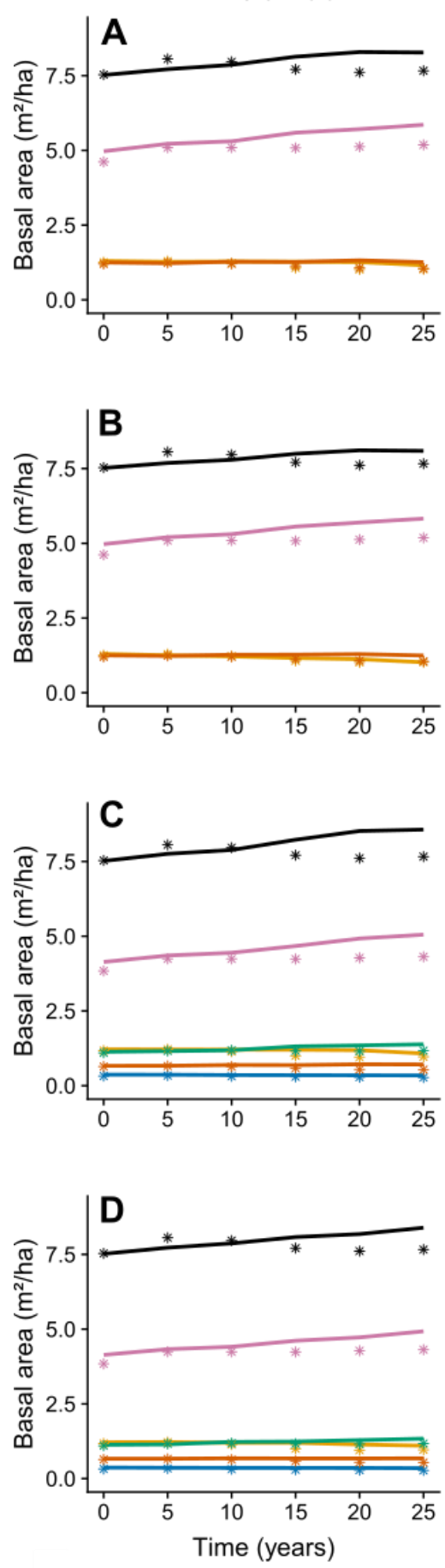

$20-60 \mathrm{~cm} \mathrm{dbh}$
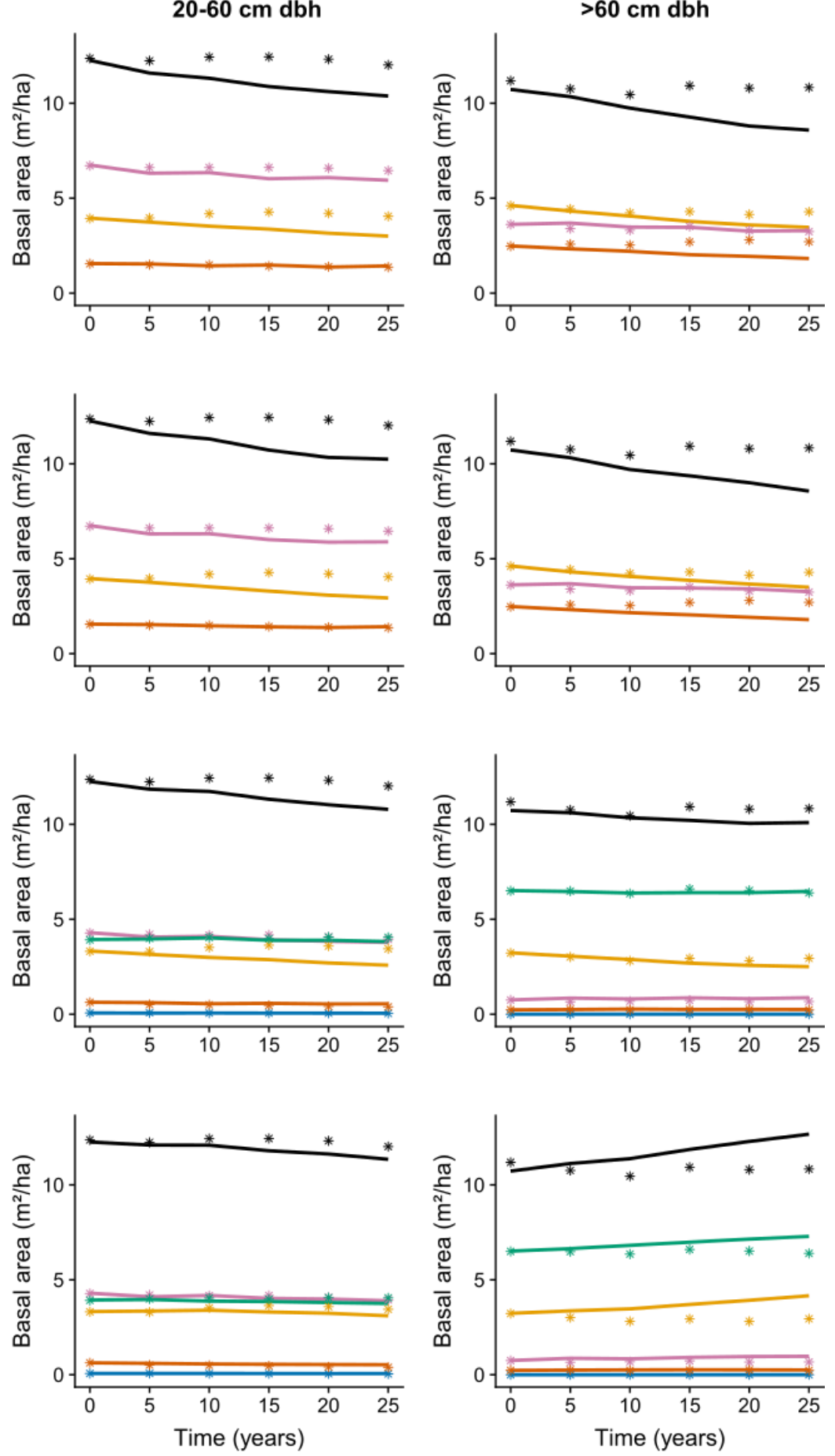

Fig. S4.

Predicted and observed basal area in four model scenarios (rows; A: 1 tradeoff -3 PFTs, B: 1 tradeoff - 282 species, C: 2 tradeoffs - 5 PFTs, D: 2 tradeoffs -282 species) and three size classes (columns). Simulated (lines) and observed (asterisks) basal area by PFT in an old-growth tropical forest in Barro Colorado Island. Color code: purple - slow, yellow - fast, green - LLP, blue - SLB, red - intermediate, black - total. 

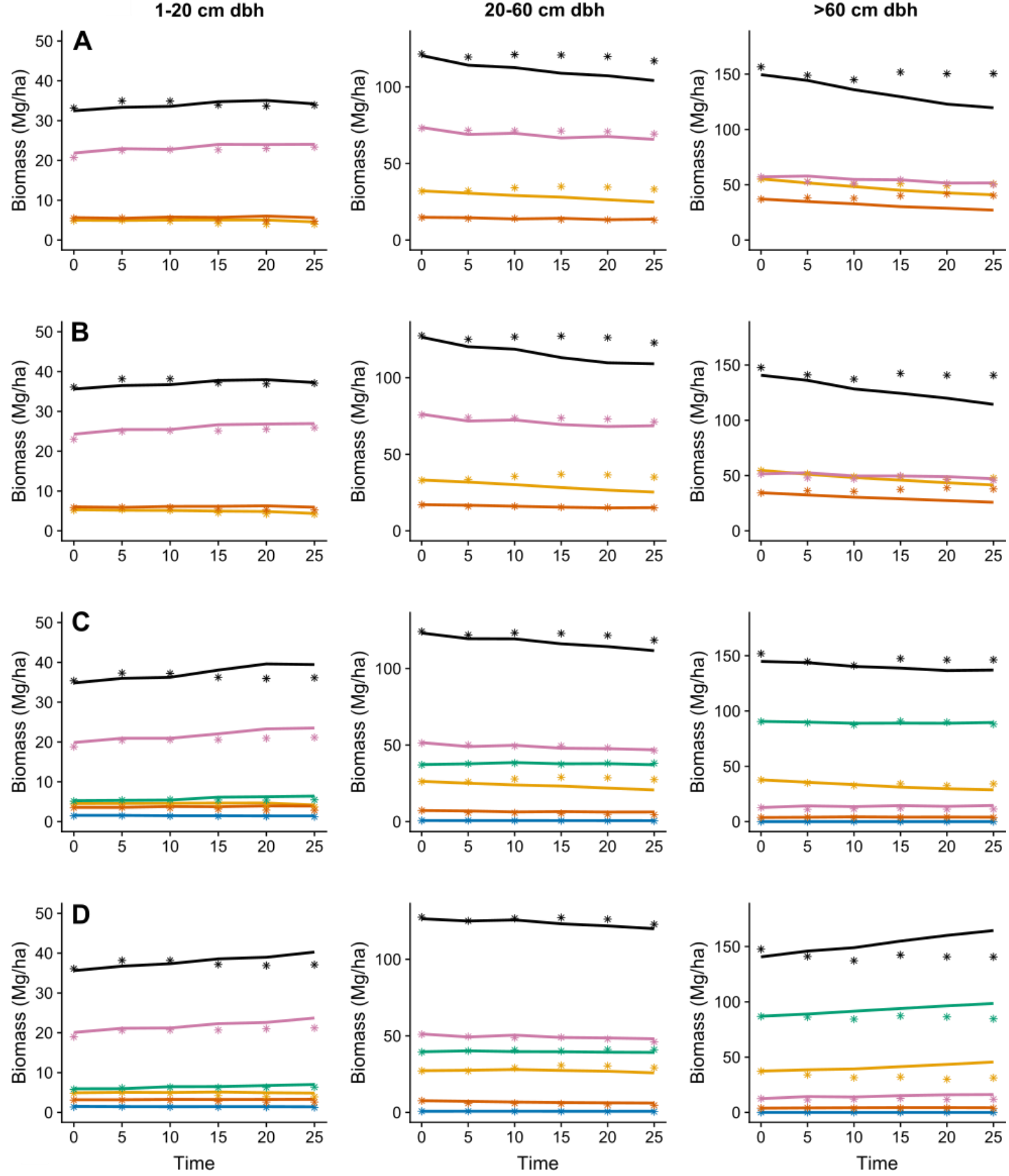

\section{Fig. S5.}

Predicted and observed aboveground biomass (AGB) in four model scenarios (rows; A: 1 tradeoff -3 PFTs, B: 1 tradeoff -282 species, C: 2 tradeoffs -5 PFTs, D: 2 tradeoffs -282 species) and three size classes (columns). Simulated (lines) and observed (asterisks) biomass by PFT in an old-growth tropical forest in Barro Colorado Island, Panama. Color code: purple slow, yellow - fast, green - LLP, blue - SLB, red - intermediate, black - total. 

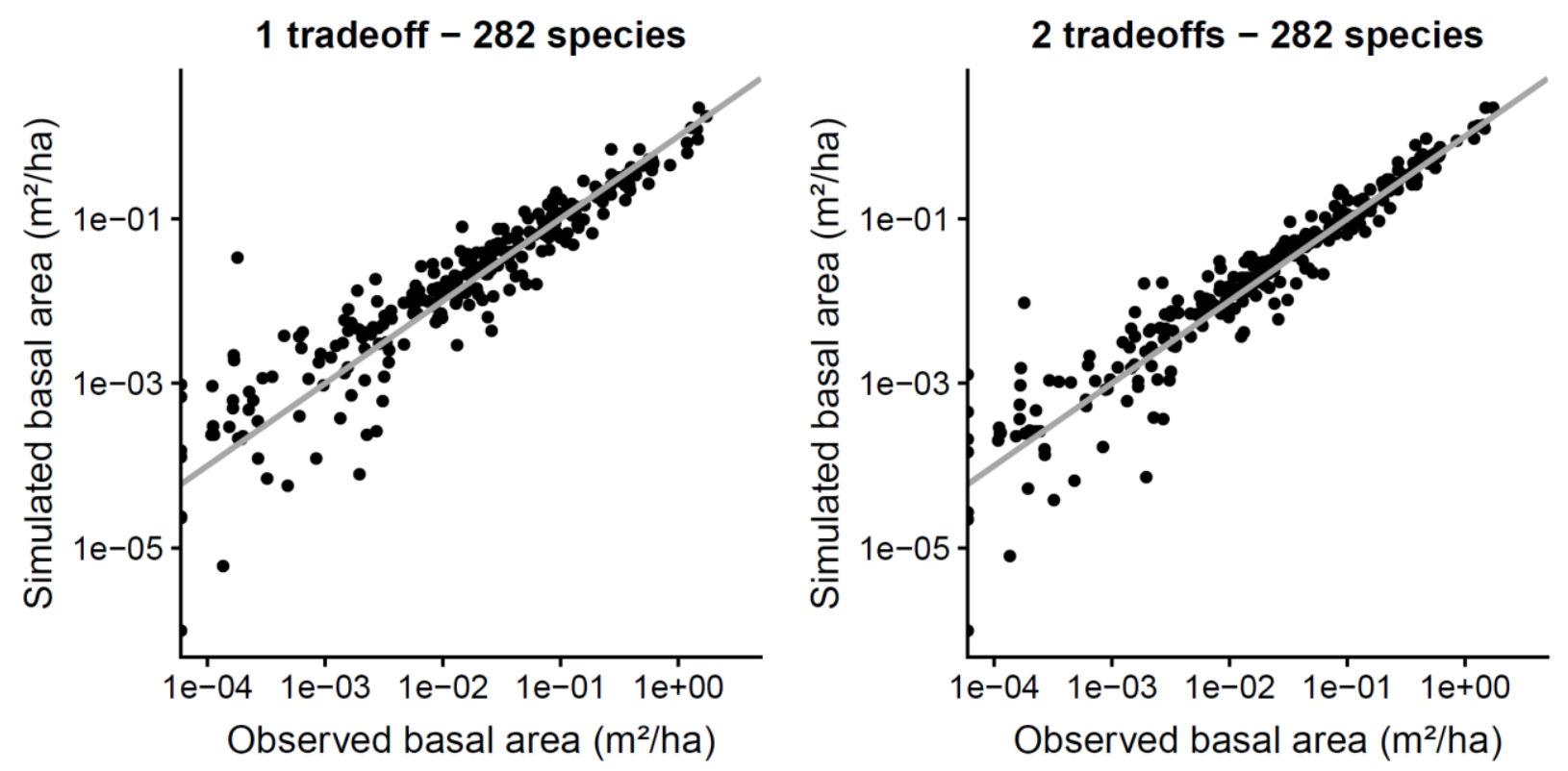

Fig. S6.

Simulated and observed basal area by species in 2010, i.e. after 25 years of simulation. 1:1 lines are shown in grey. 

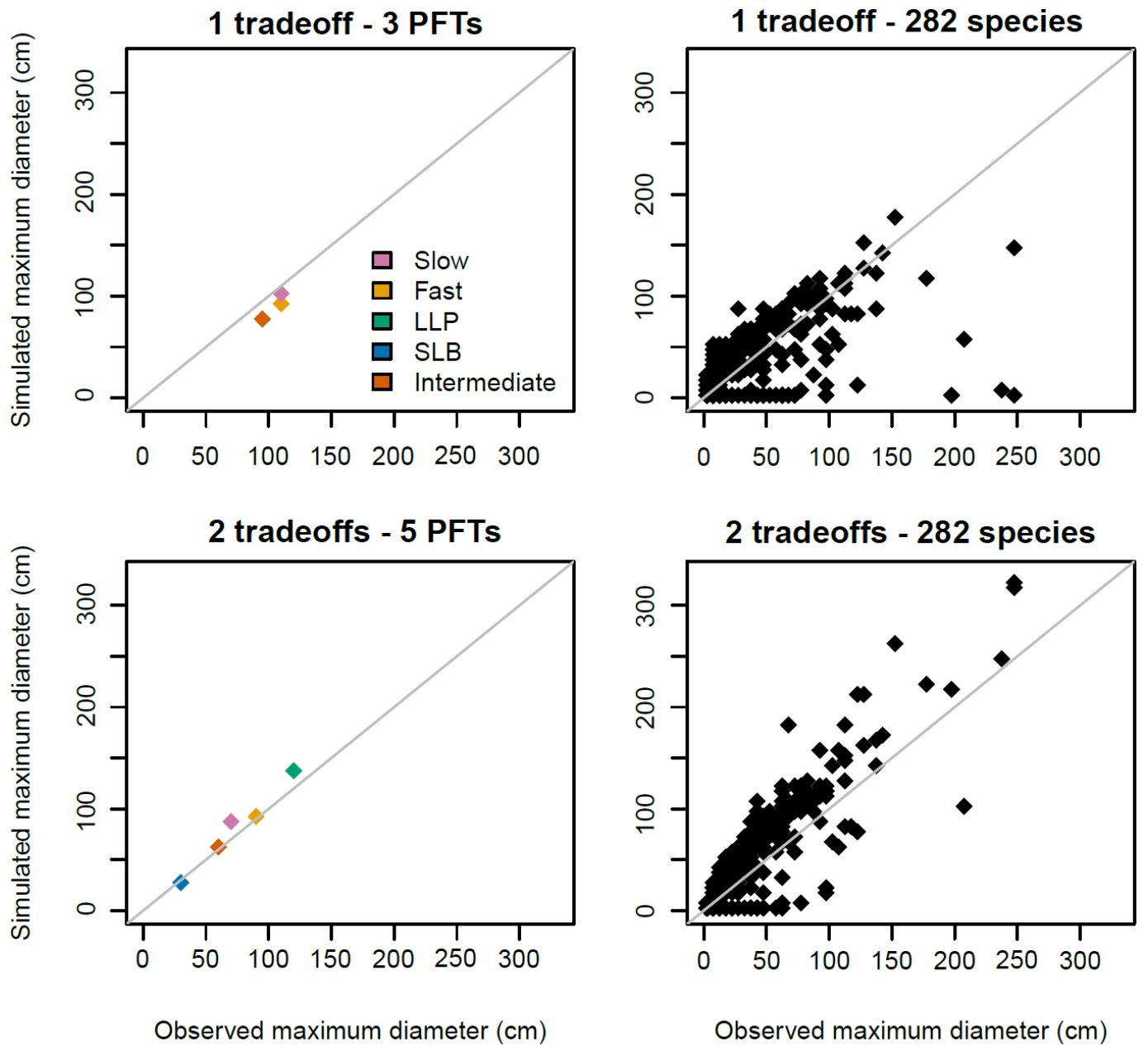

Fig. S7.

Simulated and observed maximum diameters of the PFTs or species for four model scenarios. 1:1 lines are shown in grey. See Suppl. for details. 
$5-20 \mathrm{~cm} \mathrm{dbh}$
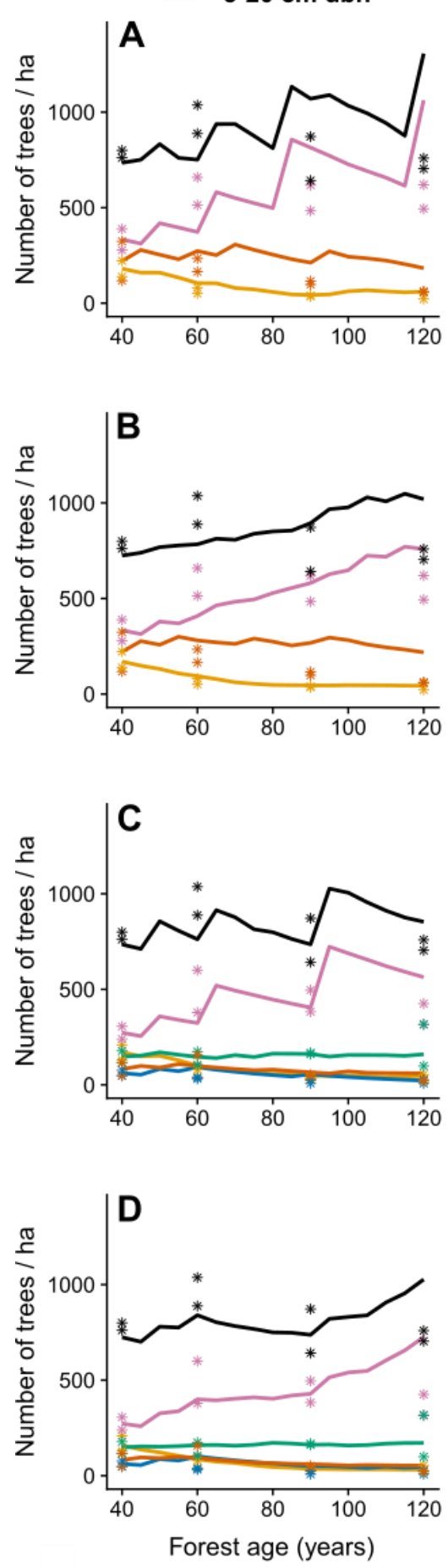

$20-60 \mathrm{~cm} \mathrm{dbh}$
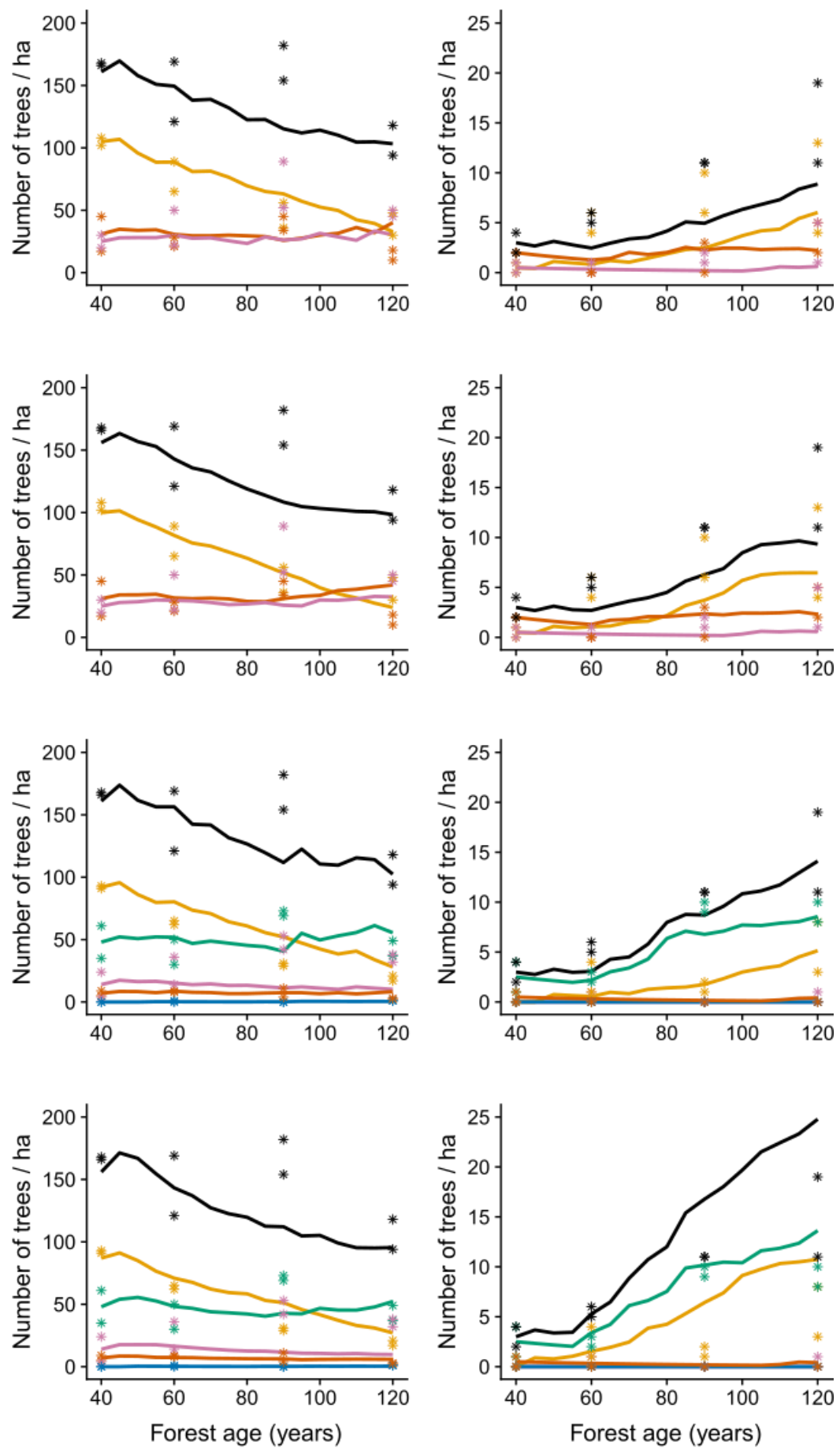

Fig. S8.

Predicted and observed abundance in four model scenarios (rows; A: 1 tradeoff -3 PFTs, B: 1 tradeoff - 282 species, C: 2 tradeoffs - 5 PFTs, D: 2 tradeoffs - 282 species) and three size classes (columns). Simulated (lines) and observed (asterisks) abundance by PFT in secondary tropical forest in Barro Colorado Nature Monument National Park, Panama. Color code: purple slow, yellow - fast, green - LLP, blue - SLB, red - intermediate, black - total. 
$5-20 \mathrm{~cm}$ dbh
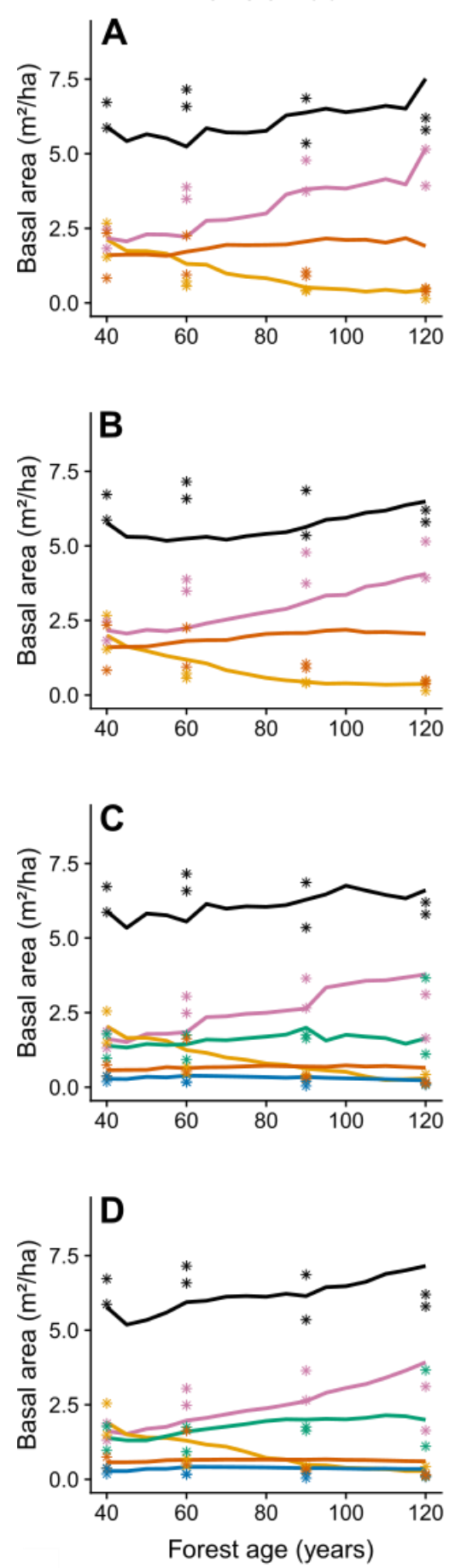

$20-60 \mathrm{~cm}$ dbh
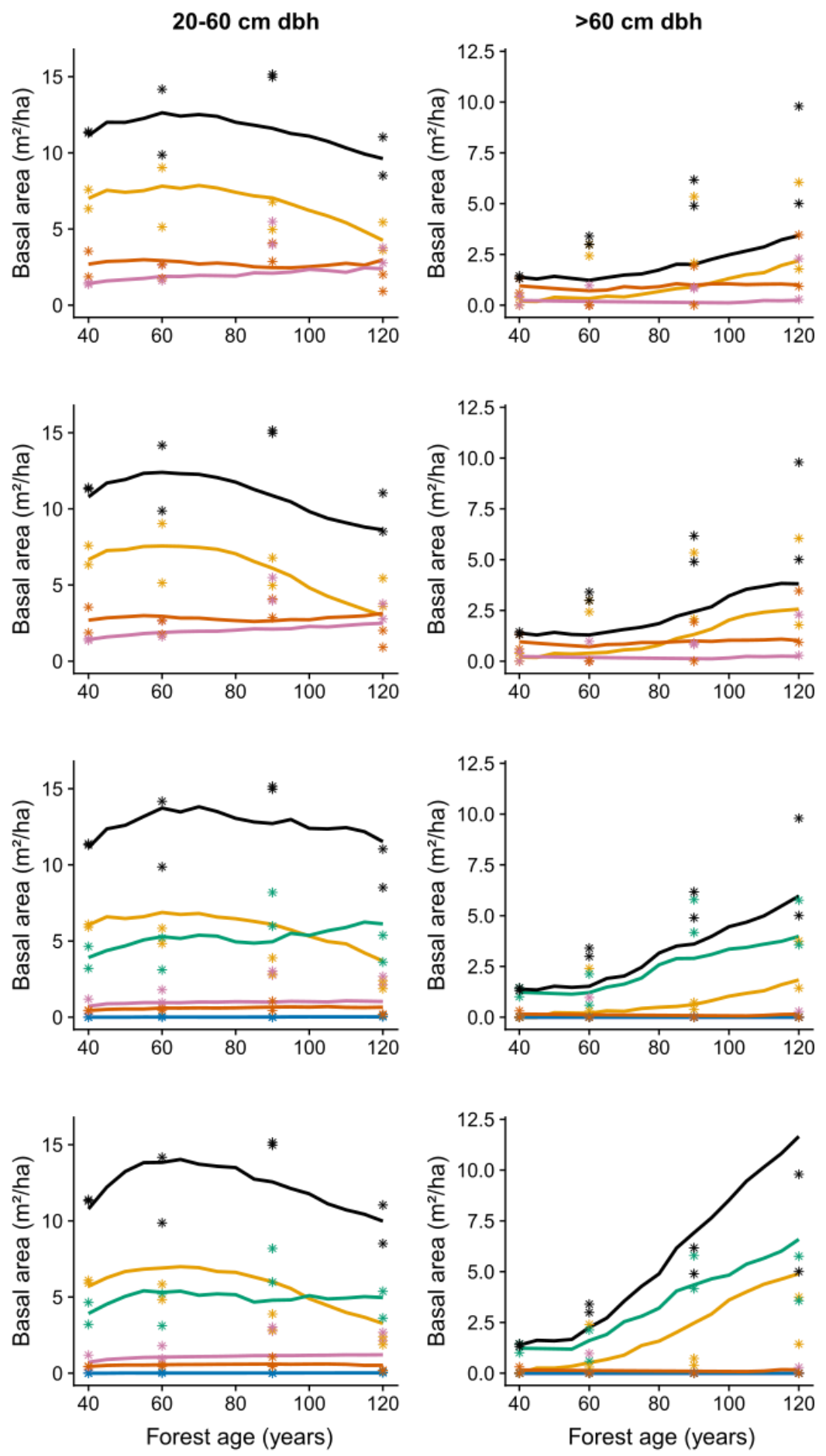

Fig. S9.

Predicted and observed basal area in four model scenarios (rows; A: 1 tradeoff - 3 PFTs, B: 1 tradeoff -282 species, C: 2 tradeoffs - 5 PFTs, D: 2 tradeoffs - 282 species) and three size classes (columns). Simulated (lines) and observed (asterisks) basal area by PFT in secondary tropical forest in Barro Colorado Nature Monument National Park, Panama. Color code: purple slow, yellow - fast, green - LLP, blue - SLB, red - intermediate, black - total. 
$5-20 \mathrm{~cm} \mathrm{dbh}$
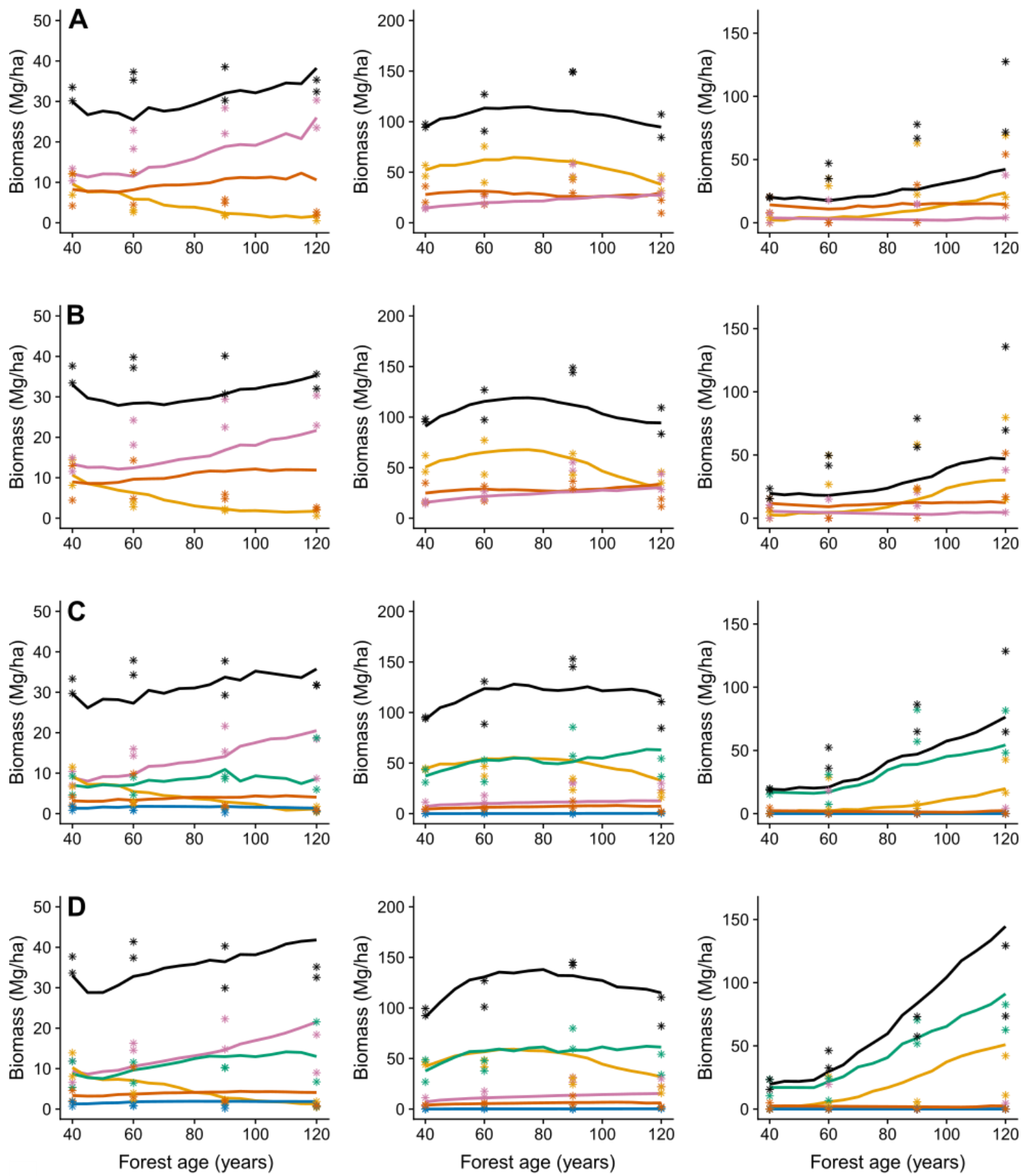

\section{Fig. S10.}

Predicted and observed aboveground biomass (AGB) area in four model scenarios (rows; A: 1 tradeoff -3 PFTs, B: 1 tradeoff - 282 species, C: 2 tradeoffs -5 PFTs, D: 2 tradeoffs -282 species) and three size classes (columns). Simulated (lines) and observed (asterisks) biomass by PFT in secondary tropical forest in Barro Colorado Nature Monument National Park, Panama. Color code: purple - slow, yellow - fast, green - LLP, blue - SLB, red - intermediate, black total. 

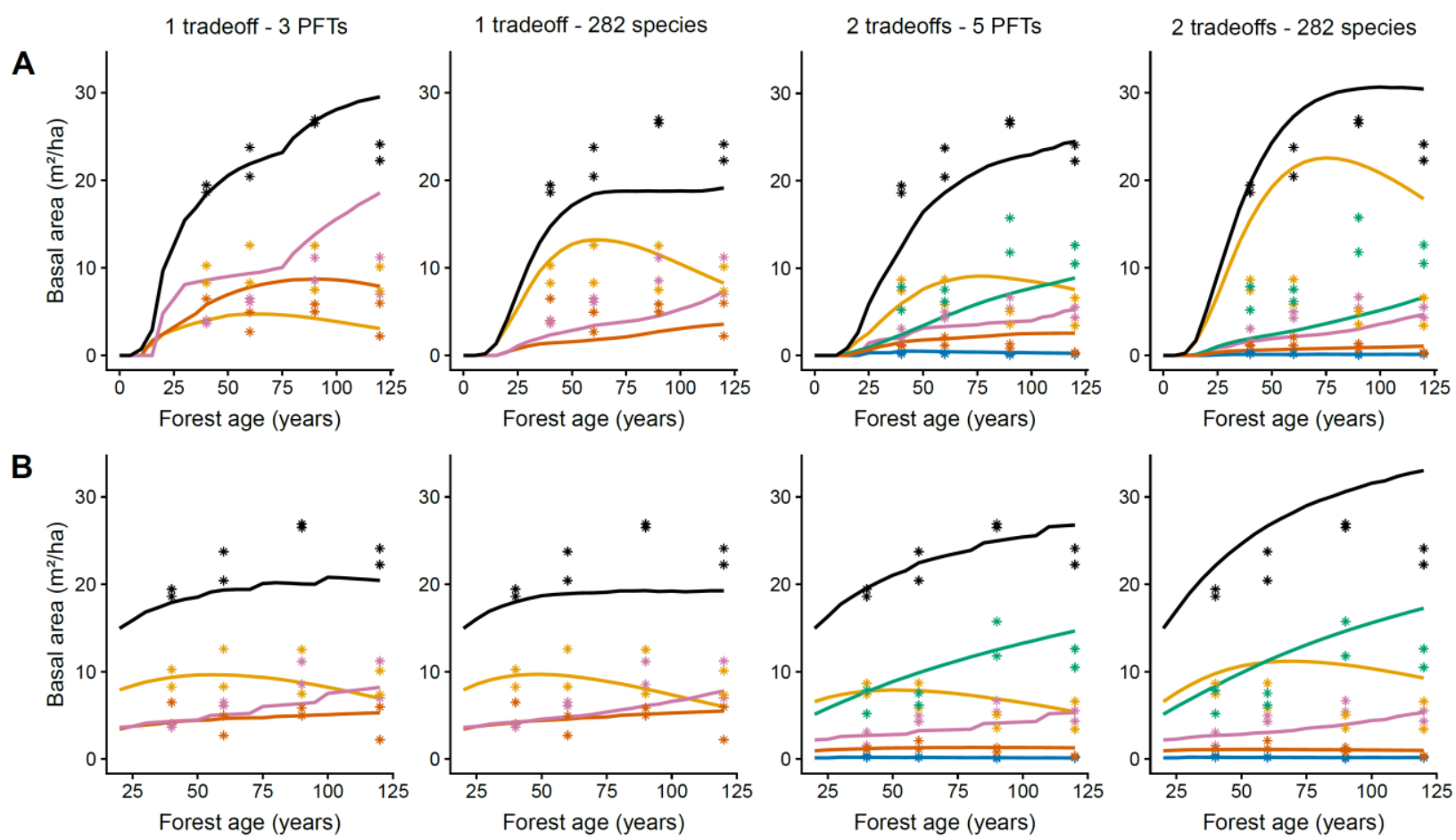

Fig. S11.

Predictions of forest recovery for four model scenarios that differ in the number and demographic characteristics of simulated species or PFTs. (A) Simulation of forest recovery from bare ground using gap-recruitment rates for the first 25 years of the simulation and oldgrowth recruitment rates thereafter. (B) Simulation of forest recovery starting from 20-year-old secondary forests. Asterisks show observed basal area by PFT in secondary tropical forest in the Barro Colorado Nature Monument National Park, Panama ( $\geq 5 \mathrm{~cm}$ dbh). Color code: purple slow, yellow - fast, green - LLP, blue - SLB, red - intermediate, black - total. 

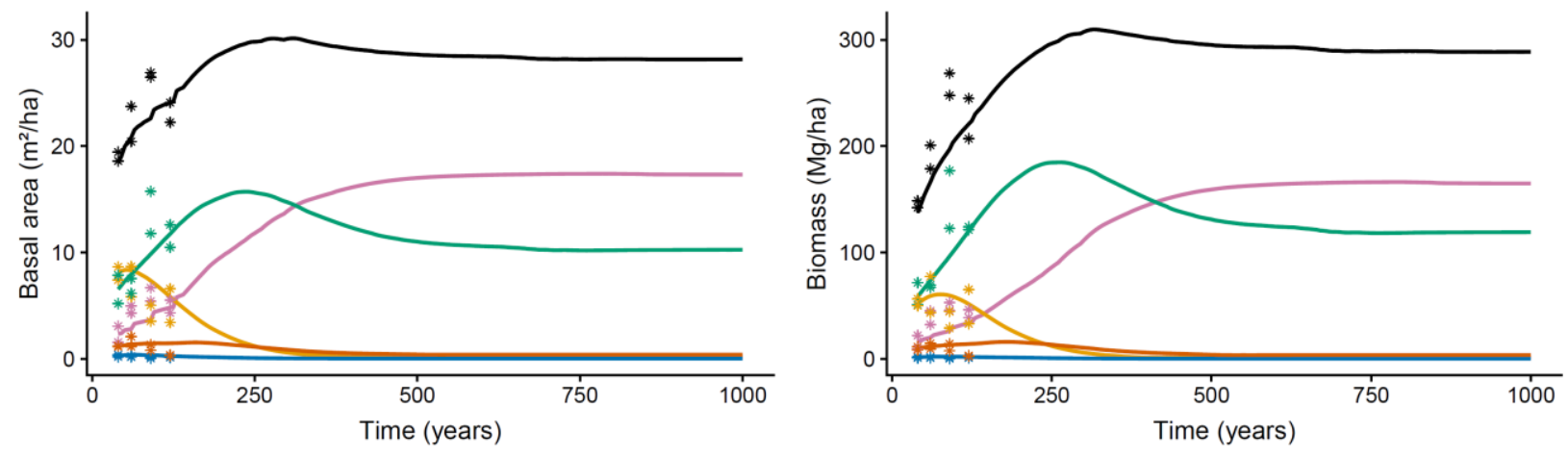

Fig. S12.

Simulated long-term succession of scenario 3 (2 tradeoffs - 5 PFTs) starting from 40-year-old secondary forest. Lines show simulated basal area and aboveground biomass of individuals $\geq 5$ $\mathrm{cm} \mathrm{dbh}$, asterisks show data from secondary forests. Recruitment rates of the PFTs are constant and set to annual averages of the number of observed recruits of species assigned to the five PFTs. Color code: purple - slow, yellow - fast, green - LLP, blue - SLB, red - intermediate, black - total. 


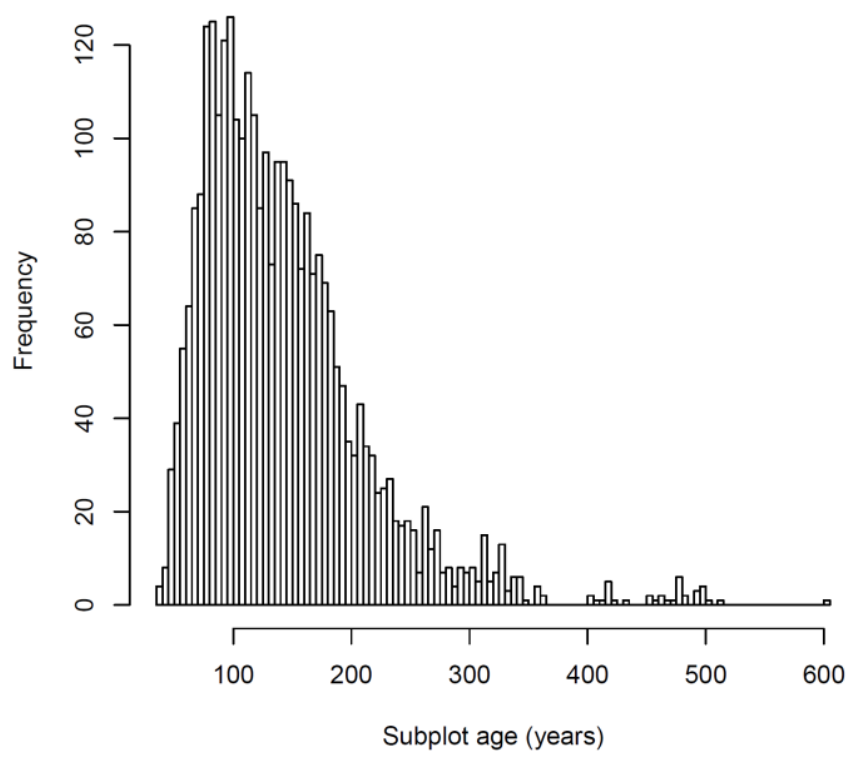

Fig. S13.

Estimated age distribution of $~ 0.1$-ha subplots from six censuses $(1985,1990,1995,2000,2005$, 2010). 

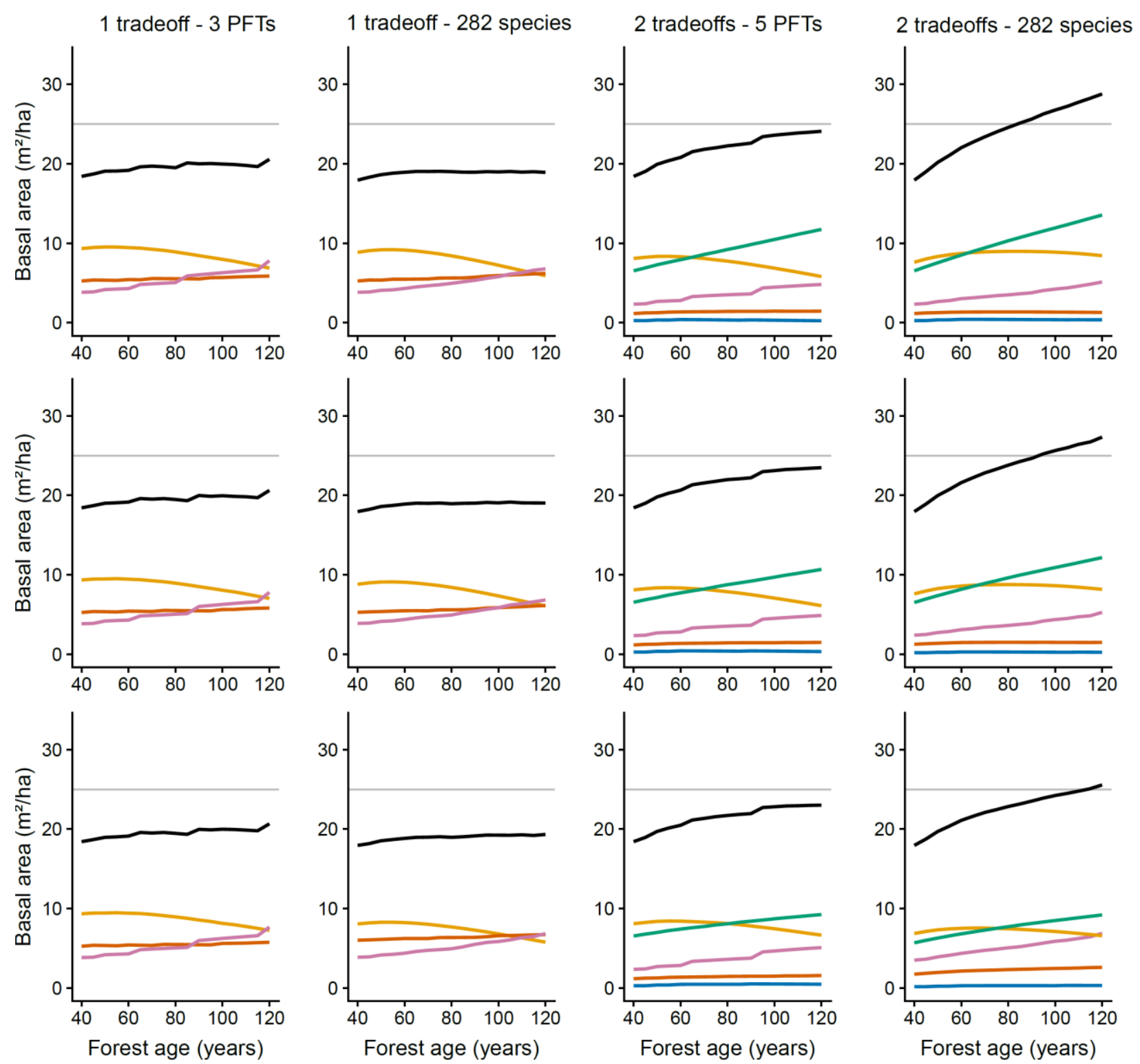

\section{Fig. S14.}

Projected forest recovery in secondary tropical forest in the Barro Colorado Nature Monument National Park, Panama, for three climate scenarios: (top) reference climate (1979-2013, repeating results from Fig. $2 \mathrm{C}$ in the main manuscript), (middle row) RCP2.6, (bottom) RCP8.5 and four model scenarios (columns). Color code: purple - slow, yellow - fast, green - LLP, blue - SLB, red - intermediate, black - total. The grey line at a basal area of $25 \mathrm{~m}^{2} / \mathrm{ha}$ is inserted to facilitate visual comparison between model scenarios. 

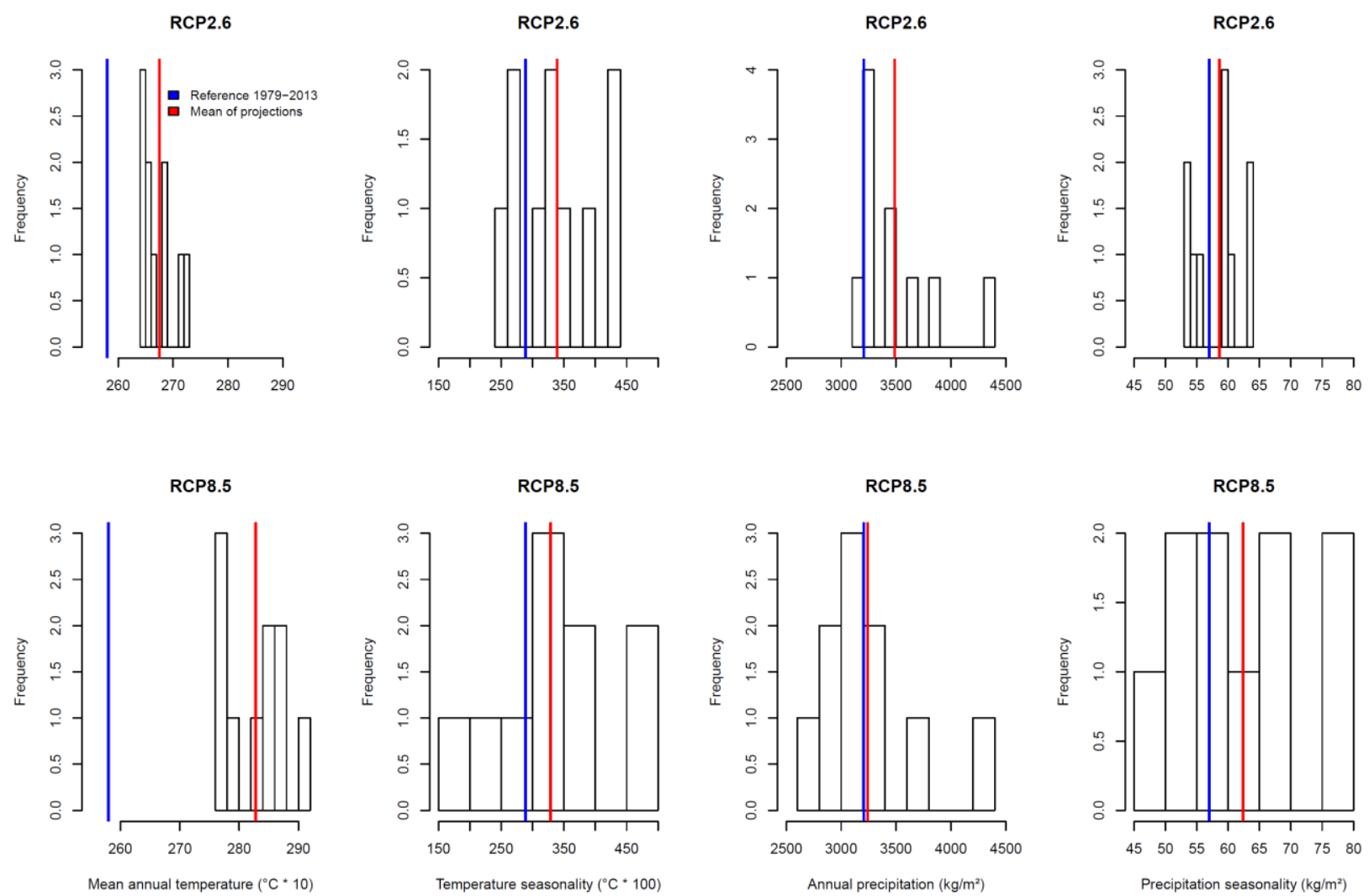

Fig. S15.

Projected climatic variables for ten global climate models. 


\section{Table S1.}

Loadings of demographic parameters in the wPCA. Survival and growth of trees $(\geq 1 \mathrm{~cm} \mathrm{dbh})$ in four canopy layers is indicated by 'Survival 1' etc. Recruitment is the number of recruits per unit of total species basal area. Only the first one or two principal components are used to backcalculate model parameters from species scores in PCA space, depending on the scenario.

\begin{tabular}{|l|l|l|l|l|l|l|l|l|l|}
\hline Parameters & \multicolumn{9}{|c|}{ Parameter loadings } \\
\hline & PC1 & PC2 & PC3 & PC4 & PC5 & PC6 & PC7 & PC8 & PC9 \\
\hline Survival1 & 0.2103 & 0.2947 & -0.5398 & -0.4130 & -0.4612 & 0.3415 & -0.2380 & 0.1407 & -0.0356 \\
\hline Survival2 & 0.3370 & 0.4051 & -0.0063 & -0.2672 & 0.3237 & 0.0814 & 0.7127 & -0.0482 & 0.1712 \\
\hline Survival3 & 0.4376 & 0.2396 & 0.2830 & 0.2505 & 0.0200 & 0.1136 & -0.4280 & -0.1090 & 0.6323 \\
\hline Survival4 & 0.4541 & 0.2032 & 0.2832 & 0.2428 & 0.1178 & 0.2067 & -0.1305 & 0.1782 & -0.7127 \\
\hline Growth1 & -0.1943 & 0.2070 & -0.6090 & 0.5235 & 0.4575 & 0.2204 & -0.0746 & -0.1046 & -0.0014 \\
\hline Growth2 & -0.3504 & 0.1586 & 0.2375 & -0.5400 & 0.5401 & 0.2434 & -0.3889 & 0.0320 & -0.0285 \\
\hline Growth3 & -0.3899 & 0.3775 & 0.1968 & 0.2308 & -0.1839 & 0.0735 & 0.1434 & 0.7262 & 0.1622 \\
\hline Growth4 & -0.3609 & 0.3588 & 0.2738 & 0.1188 & -0.3651 & 0.3276 & 0.1296 & -0.6163 & -0.1215 \\
\hline Recruitment & 0.0415 & -0.5578 & 0.0858 & 0.0571 & 0.0069 & 0.7750 & 0.2025 & 0.1228 & 0.1404 \\
\hline
\end{tabular}




\section{Table S2.}

PPA model parameters for 3 PFTs (1 demographic tradeoff axis). G1 to G4 and mu1 to mu4 are annual growth $(\mathrm{mm} / \mathrm{y})$ and mortality $(1 / \mathrm{y})$ rates in four canopy layers, respectively. $\mathrm{F}$ is the number of new recruits over the $1 \mathrm{~cm}$ dbh threshold per year and hectare and wd is volumeweighted wood density $\left(\mathrm{g} / \mathrm{cm}^{3}\right)$ in old-growth $(\mathrm{OG})$ and secondary (SEC) forest.

\begin{tabular}{|l|l|l|l|l|l|l|l|l|l|l|l|}
\hline PFT & \multicolumn{9}{|c|}{ Model parameters } \\
& G1 & G2 & G3 & G4 & mu1 & mu2 & mu3 & mu4 & F & wd_OG & wd_SEC \\
\hline slow & 2.46028 & 0.68289 & 0.40415 & 0.36858 & 0.0174 & 0.0097 & 0.01037 & 0.01641 & 79.22 & 0.566 & 0.613 \\
\hline fast & 4.34277 & 2.21993 & 0.89384 & 0.67679 & 0.02851 & 0.02614 & 0.04981 & 0.06728 & 22.65 & 0.412 & 0.423 \\
\hline $\begin{array}{l}\text { inter- } \\
\text { mediate }\end{array}$ & 3.2687 & 1.23125 & 0.60104 & 0.49945 & 0.02227 & 0.01592 & 0.02272 & 0.03323 & 12.62 & 0.503 & 0.542 \\
\hline
\end{tabular}

\section{Table S3.}

PPA model parameters for 5 PFTs (2 demographic tradeoff axes). G1 to G4 and mu1 to mu4 are annual growth $(\mathrm{mm} / \mathrm{y})$ and mortality $(1 / \mathrm{y})$ rates in four canopy layers, respectively. $\mathrm{F}$ is the number of new recruits over the $1 \mathrm{~cm}$ dbh threshold per year and hectare and wd is volumeweighted wood density $\left(\mathrm{g} / \mathrm{cm}^{3}\right)$ in old-growth (OG) and secondary (SEC) forest.

\begin{tabular}{|l|l|l|l|l|l|l|l|l|l|l|l|}
\hline PFT & \multicolumn{10}{|c|}{ Model parameters } \\
\hline & G1 & G2 & G3 & G4 & mu1 & mu2 & mu3 & mu4 & F & wd_OG & wd_SEC \\
\hline slow & 2.46028 & 0.68289 & 0.40415 & 0.36858 & 0.0174 & 0.0097 & 0.01037 & 0.01641 & 65.37 & 0.635 & 0.624 \\
\hline fast & 4.34277 & 2.21993 & 0.89384 & 0.67679 & 0.02851 & 0.02614 & 0.04981 & 0.06728 & 20.83 & 0.403 & 0.421 \\
\hline LLP & 4.42383 & 1.6079 & 0.88258 & 0.67557 & 0.01576 & 0.00877 & 0.01479 & 0.02423 & 6.22 & 0.480 & 0.504 \\
\hline SLB & 2.4152 & 0.94283 & 0.40931 & 0.36925 & 0.03148 & 0.0289 & 0.03492 & 0.04557 & 16.83 & 0.653 & 0.611 \\
\hline $\begin{array}{l}\text { inter- } \\
\text { mediate }\end{array}$ & 3.2687 & 1.23125 & 0.60104 & 0.49945 & 0.02227 & 0.01592 & 0.02272 & 0.03323 & 6.24 & 0.600 & 0.594 \\
\hline
\end{tabular}


Table S4.

Means of model projections for climatic variables.

\begin{tabular}{|l|l|l|l|l|}
\hline Scenario & Temperature & Precipitation & $\begin{array}{l}\text { Temperature } \\
\text { seasonality }\end{array}$ & $\begin{array}{l}\text { Precipitation } \\
\text { seasonality }\end{array}$ \\
\hline Reference (1979-2013) & 258.0 & 3206.0 & 289.0 & 57.0 \\
\hline RCP2.6 (2061-2080) & 267.5 & 3487.3 & 339.0 & 58.6 \\
\hline RCP8.5 (2061-2080) & 282.8 & 3240.5 & 328.7 & 62.4 \\
\hline
\end{tabular}

Table S5.

Most parsimonious models (based on AICc) using the dredge function in the 'MuMIn' package in $\mathrm{R}$.

\begin{tabular}{|l|l|l|l|l|l|l|l|l|l|}
\hline & $\mathrm{T}$ & $\mathrm{T}^{2}$ & $\mathrm{P}$ & $\mathrm{P}^{2}$ & $\mathrm{TS}$ & $\mathrm{TS}^{2}$ & $\mathrm{PS}$ & $\mathrm{PS}^{2}$ & $\mathrm{R}^{\mathbf{2}}$ \\
\hline Mean Log Height & & $\mathrm{x}$ & $\mathrm{x}$ & $\mathrm{x}$ & $\mathrm{x}$ & $\mathrm{x}$ & $\mathrm{x}$ & $\mathrm{x}$ & 0.76 \\
\hline SD Log Height & & $\mathrm{x}$ & $\mathrm{x}$ & $\mathrm{x}$ & $\mathrm{x}$ & $\mathrm{x}$ & $\mathrm{x}$ & & 0.74 \\
\hline Mean Log Seed Mass & & $\mathrm{x}$ & $\mathrm{x}$ & $\mathrm{x}$ & $\mathrm{x}$ & $\mathrm{x}$ & $\mathrm{x}$ & & 0.71 \\
\hline $\begin{array}{l}\text { Mean Log Wood } \\
\text { Density }\end{array}$ & $\mathrm{x}$ & $\mathrm{x}$ & $\mathrm{x}$ & $\mathrm{x}$ & $\mathrm{x}$ & & $\mathrm{x}$ & $\mathrm{x}$ & 0.29 \\
\hline SD Log Wood Density & $\mathrm{x}$ & $\mathrm{x}$ & $\mathrm{x}$ & $\mathrm{x}$ & & & & $\mathrm{x}$ & 0.41 \\
\hline
\end{tabular}

Table S6.

Projected changes in functional traits using climate-trait models from Šímova et al. (29). Differences between climate projections and the reference climate are shown in bold.

\begin{tabular}{|l|l|l|l|l|l|}
\hline Scenario & $\begin{array}{l}\text { Log Height } \\
(\text { mean) }\end{array}$ & $\begin{array}{l}\text { Log Height } \\
(\text { SD) }\end{array}$ & $\begin{array}{l}\text { Log Seed } \\
\text { Mass }\end{array}$ & $\begin{array}{l}\text { Log Wood } \\
\text { Density (mean) }\end{array}$ & $\begin{array}{l}\text { Log Wood } \\
\text { Density (SD) }\end{array}$ \\
\hline Reference (1979-2013) & 2.91 & 0.73 & 4.48 & -0.50 & 0.095 \\
\hline RCP2.6 (2061-2080) & 2.93 & 0.65 & 4.64 & -0.47 & 0.087 \\
& $\mathbf{( + 0 . 0 2 )}$ & $\mathbf{( - 0 . 0 8 )}$ & $\mathbf{( + 0 . 1 6 )}$ & $\mathbf{( + 0 . 0 3 )}$ & $\mathbf{( - 0 . 0 0 8 )}$ \\
\hline RCP8.5 (2061-2080) & 2.98 & 0.51 & 4.88 & -0.43 & 0.067 \\
& $\mathbf{( + 0 . 0 7 )}$ & $\mathbf{( - 0 . 2 2 )}$ & $\mathbf{( + 0 . 4 0 )}$ & $\mathbf{( + 0 . 0 7 )}$ & $\mathbf{( - 0 . 0 2 8 )}$ \\
\hline
\end{tabular}




\section{Table S7.}

Projected changes in functional traits at BCI. Projected trait values at BCI were determined by adding the trait differences from Table S6 to current trait means and SDs.

\begin{tabular}{|l|l|l|l|l|l|}
\hline Scenario & $\begin{array}{l}\text { Log Height } \\
(\text { mean })\end{array}$ & $\begin{array}{l}\text { Log Height } \\
(\text { SD) }\end{array}$ & $\begin{array}{l}\text { Log Seed } \\
\text { mass (mean) }\end{array}$ & $\begin{array}{l}\text { Log Wood } \\
\text { density (mean) }\end{array}$ & $\begin{array}{l}\text { Wood density } \\
\text { (SD) }\end{array}$ \\
\hline BCI now & 2.62 & 0.74 & 3.44 & -0.63 & 0.138 \\
\hline BCI RCP2.6 & 2.64 & 0.66 & 3.60 & -0.60 & 0.130 \\
$(2061-2080)$ & $\mathbf{( + 0 . 0 2 )}$ & $\mathbf{( - 0 . 0 8 )}$ & $\mathbf{( + 0 . 1 6 )}$ & $\mathbf{( + 0 . 0 3 )}$ & $\mathbf{( - 0 . 0 0 8 )}$ \\
\hline BCI RCP8.5 & 2.69 & 0.52 & 3.84 & -0.56 & 0.110 \\
$(2061-2080)$ & $\mathbf{( + 0 . 0 7 )}$ & $\mathbf{( - 0 . 2 2 )}$ & $\mathbf{( + 0 . 4 0 )}$ & $\mathbf{( + 0 . 0 7 )}$ & $\mathbf{( - 0 . 0 2 8 )}$ \\
\hline
\end{tabular}

\section{Table S8.}

Projected changes in the coordinates of tree species in a two-dimensional demographic space, where $\mathrm{x}$ corresponds to the fast-slow continuum and $\mathrm{y}$ to the stature-recruitment tradeoff (9).

\begin{tabular}{|l|l|l|}
\hline Scenario & Mean x & Mean y \\
\hline BCI now & 0.133 & 0.181 \\
\hline BCI RCP2.6 (2061-2080) & 0.274 & 0.205 \\
& $\mathbf{( + 0 . 1 4 0 )}$ & $\mathbf{( + 0 . 0 2 4 )}$ \\
\hline BCI RCP8.5 (2061-2080) & 0.455 & 0.270 \\
& $\mathbf{( + 0 . 3 2 2 )}$ & $\mathbf{( + 0 . 0 8 9 )}$ \\
\hline
\end{tabular}




\section{Data S1. (separate file)}

Species scores in PCA space, PFT assignments, and model parameters for 282 tree and shrub species at Barro Colorado Island, Panama.

Data S2. (separate file)

Assignment of plant functional types (PFT) for species from secondary forest plots for which no demographic information was available from old-growth forest.

\section{Simulation code (separate file)}

Simulation model code, written in R, for 5 PFTs: PPA_5PFTs_4layers.r 